\title{
LA NATURALEZA BIFRONTE DEL ESTADO DE ALARMA Y EL DILEMA LIMITACIÓN-SUSPENSIÓN DE DERECHOS
}

\author{
CARLOS GARRIDO LÓPEZ \\ Profesor titular de Derecho Constitucional \\ Universidad de Zaragoza
}

TRC, núm. 46, 2020, pp. 371-402

ISSN 1139-5583

\begin{abstract}
SUMARIO
I. Introducción. II. La naturaleza bifronte del estado de alarma en el proceso constituyente y en la LOAES. III. El estado de alarma como instrumento extraordinario frente a calamidades naturales, crisis sanitarias y emergencias de naturaleza social. Su declaración en diciembre de 2010 y marzo de 2020. IV. El cuestionamiento de los estados de alarma declarados en 2010 y 2020 y la falsa disyuntiva entre la declaración de alarma o de excepción. V. Alcance y límites de las medidas extraordinarias a adoptar. La distinción entre limitación y suspensión de derechos. VI. La militarización de los controladores de tránsito aéreo bajo el estado de alarma de 2010. VII. La polémica sobre la limitación o la suspensión de derechos en el estado de alarma declarado para gestionar la crisis sanitaria de la COVID-19. VIII. Consideraciones finales.
\end{abstract}

\section{INTRODUCCIÓN}

El estado de alarma ha tenido en nuestro país una existencia paradójica. Durante décadas, pese a acaecer incendios, inundaciones y catástrofes medioambientales como la del Prestige, ningún estado de alarma fue declarado. La clase política lo consideraba un recurso de otro tiempo. Y la doctrina subrayó su dudosa utilidad tanto para superar conflictos sociales como para enfrentar calamidades naturales, sanitarias y tecnológicas. El legislador, receloso de la posible reedición del estado de prevención de 1933, dificultó el uso del estado de alarma frente a emergencias de naturaleza político-social. Y al prever en la legislación sectorial sobre protección civil, sanidad y medio ambiente la adopción de diversas medidas 
de emergencia sin las formalidades del estado de alarma, también redujo su funcionalidad en esos ámbitos. «En puridad, el estado de alarma y la nada son la misma cosa —afirmó Carro Martínez-, porque las facultades de la autoridad son las mismas que le corresponden en períodos de normalidad» ${ }^{1}$. $\mathrm{Y}$ en la misma línea, Cruz Villalón llegó a hablar de «la desuetudo» de las previsiones del artículo 116 de la CE, en general, y del estado de alarma, en particular ${ }^{2}$.

Pero, a la postre, nada más lejos de la realidad, porque, superados los prejuicios hacia su utilización, el estado de alarma ha demostrado ser un instrumento constitucional versátil y sumamente funcional, al lograr, con ocasión de su primera declaración en diciembre de 2010, restablecer el servicio público esencial de transporte aéreo, paralizado por sus propios controladores, y reducir, en sus posteriores declaraciones durante la primavera de 2020 y en octubre del mismo año, el número de contagios y el impacto sobre la salud pública del coronavirus COVID-19. En el primer caso, la normalización del tránsito aéreo se produjo mediante la militarización de los controladores en apenas unos días desde la declaración del estado de alarma. En el segundo, la severa restricción de la libertad circulatoria y el confinamiento domiciliario impuestos en la declaración han detenido la expansión de «una pandemia global muy grave, que ha producido un gran número de afectados y muertos en nuestro país, y que ha puesto a prueba a las instituciones y a la propia sociedad» (ATC 40/2020, de 30 de abril, FJ 2). Como no podía ser de otra manera, la eficacia excepcional del estado de alarma ha sido reconocida en ambas ocasiones, pero lo cierto es que, también en ambas, su declaración y su contenido han suscitado reproches doctrinales, airadas críticas políticas y la interposición de una catarata de recursos contencioso-administrativos por la vía de protección jurisdiccional de los derechos de la persona, de recursos de amparo ante el Tribunal Constitucional e, incluso, en el caso del estado de alarma sanitaria, de un recurso de inconstitucionalidad, presentado por los diputados del grupo parlamentario Vox, pendiente de resolución. Nadie ha negado el deber que asiste al Estado de proteger a la comunidad, pero, puesto a hacerlo, se ha sostenido en ambos casos que el instrumento adecuado no era el estado de alarma, sino el de excepción, y que las medidas excepcionales adoptadas suponían una auténtica suspensión de derechos. Y a la par que se sostenía esto, también se afirmaba lo contrario: que para superar ambas crisis bastaban las potestades ordinarias previstas en la legislación sectorial correspondiente. Se ha pasado así, sin solución de continuidad, de subrayar la desuetudo del estado de alarma a denunciar su utilización, bien por estimarlo insuficiente o por considerarlo innecesario y abusivo.

En este trabajo analizaré los fundamentos y el alcance constitucional de esta polémica. En primer lugar, estudiaré la naturaleza bifronte con que el estado de

1 A. Carro Martínez, «Artículo 116. Situaciones de anormalidad constitucional», O. Alzaga Villaamil (dir.), Comentarios a la Constitución española de 1978, tomo IX, Edersa-Cortes Generales, Madrid, 1998, p. 253.

2 P. Cruz Villalón, «Normalidad y excepción», REDC, n. ํ 71, 2004, p. 192. 
alarma fue constitucionalizado, la desnaturalización que experimentó en su configuración legal y las dificultades interpretativas que suscita su activación ante situaciones de conflictividad social y otras emergencias que desbordan su marco jurídico. En segundo lugar, replicaré los argumentos que han cuestionado la declaración del estado de alarma en 2010 y 2020 y expondré las razones por las que, a mi juicio, el debate entre alarma y excepción encierra, en ambos casos, una falsa disyuntiva. Seguidamente, analizaré el problema de la distinción entre limitación y suspensión de derechos que plantea nuestro modelo de excepción, las críticas que desencadenó la militarización de los controladores de tránsito aéreo y el intenso debate doctrinal que han generado las restricciones a la libertad de circulación, la reclusión domiciliaria y la afección de otros derechos conexos, como los de reunión, manifestación y sufragio, durante la crisis de la COVID-19. Por último, tras subrayar las deficiencias de lege lata y los límites de la ponderación para salvarlas, formularé varias propuestas de lege ferenda con las que adaptar el proyecto normativo del estado de alarma a sus condiciones de realización.

\section{LA NATURALEZA BIFRONTE DEL ESTADO DE ALARMA EN EL PROCESO CONSTITUYENTE Y EN LA LOAES}

Frente a las cláusulas generales de apoderamiento, los bills of indemnity y los plenos poderes, el modelo de estado excepcional constituye el máximo esfuerzo por extender el imperio de la ley a las situaciones excepcionales, al prever una legalidad latente alternativa a la ordinaria con que poder hacerles frente. En este modelo también se potencia la eficacia y la concentración del poder, pero sin renunciar a la fuerza normalizadora del derecho, porque con arreglo a derecho se encara la excepción, se actúa durante ella y se liquidan sus consecuencias ${ }^{3}$. «Llamamos estado excepcional — subrayó Cruz Villalón- al derecho de excepción basado en el mantenimiento sustancial del orden constitucional incluso en situaciones de crisis, si bien con la previsión de una serie de competencias extraordinarias taxativamente enumeradas que suponen la suspensión de la Constitución en algunos de sus extremos» ${ }^{4}$. No hay, sin embargo, paradoja en ello, pese a lo sostenido por Agamben, porque el estado excepcional no es un derecho al margen del derecho ${ }^{5}$. En primer lugar, porque en los estados excepcionales no se produce una suspensión completa

3 N. Pérez Serrano, Tratado de Derecho Político, 2. a ed., Civitas, Madrid, 1984, p. 418.

4 P. Cruz Villalón, Estados excepcionales y suspensión de garantías, Tecnos, Madrid, 1984, p. 31.

$5 \mathrm{El}$ modelo de estado excepcional — sostiene G. AGAMBEN— se presenta como la forma jurídica de lo que no puede adoptar forma jurídica. «Si lo propio del estado de excepción es una suspensión (total o parcial) del ordenamiento jurídico, ¿cómo puede tal suspensión estar comprendida en el orden legal», se pregunta el autor, para responder que «se trata de una articulación paradójica, porque aquello que debe estar inscrito en el interior del derecho es algo esencialmente exterior a él, ya que se corresponde, nada menos, con la suspensión del propio orden jurídico». Cfr. Estado de excepción, Adriana Hidalgo editora, Buenos Aires, 2005, pp. 59 y $72-73$. 
del derecho y, en segundo, porque dicha suspensión o excepción está definida y configurada por el propio derecho, que habilita la aplicación de un marco jurídico que sustituye a otro conforme a lo previsto en una norma superior.

Acorde con las exigencias de la Constitución normativa, el modelo de estado excepcional requiere que el constituyente $\mathrm{o}$, por expresa delegación suya, el legislador tipifique las emergencias que amenazan a la comunidad, delimitando el elenco de medidas excepcionales que cabe adoptar para superarlas. Y exige que determine el órgano competente para declarar el estado y activar los poderes de excepción, cuyo beneficiario, que puede coincidir o no con dicho órgano, actúa en el marco jurídico preestablecido sometido a control y responsabilidad.

El constituyente de 1978 (CE) optó claramente por este modelo garantista, regulando no solo un estado excepcional, sino tres, denominados estados de alarma, de excepción y de sitio. La pluralidad de estados había sido una constante en la España constitucional, pero, a excepción de la mención del estado de guerra en la Constitución de 1931, nuestras constituciones se limitaron a regular la suspensión de derechos como eventual contenido de las situaciones excepcionales, delegando en el legislador de orden público la tarea de concretar los tipos de estados y su diferente naturaleza. Esa delegación dio lugar a los estados de alarma y de guerra previstos en la Ley de González Brabo de 1867, al estado de prevención y alarma y al estado de guerra de la Ley de Orden Público de 1870 y a los estados de prevención, de alarma y de guerra de la Ley homónima de 1933, ninguno de los cuales fue constitucionalizado 6 . El constituyente de 1978 decidió, sin embargo, alterar esta dinámica, añadiendo a la previsión de la suspensión de derechos en situaciones excepcionales la garantía suplementaria de la regulación constitucional de los estados de excepción, enunciados taxativamente en el artículo 116 de la $\mathrm{CE}^{7}$. El constituyente limitó de este modo la libertad de configuración del legislador. Las formas, la competencia y el procedimiento de declaración, caracterizado "por un progresivo aumento del control ejercido por la intervención del Congreso conforme se incrementa la gravedad de la medida adoptada ${ }^{8}$, fueron aspectos plenamente constitucionalizados. Y delimitada quedó asimismo la «Constitución suspendible», pues el artículo 55.1 de la CE enuncia, con indudable carácter de numerus clausus, los derechos y libertades cuyo ejercicio puede ser restringido sensiblemente bajo los estados de excepción y sitio.

El constituyente no pretendió, con todo, agotar la regulación del derecho de excepción. Al contrario que el Verfassungsnotstand de la Ley Fundamental de

6 Sobre los estados excepcionales en nuestra historia constitucional, F. FERnÁndez SEgAdo, El estado de excepción en el derecho constitucional español, Edersa, Madrid, 1977, pp. 92-102, 121-144 y 225-264, quien da cuenta, asimismo, de los estados de excepción y de guerra regulados, bajo el franquismo, en la Ley de Orden Público de 1959.

7 P. Cruz Villalón, Estados excepcionales y suspensión de garantías, cit., p. 50.

8 I. Berdugo Gómez De La Torre, «Garantías en la Constitución ante la suspensión de derechos fundamentales», Sistema, n. ${ }^{\circ} 42,1981$, p. 63. 
Bonn, los estados de anomalía previstos en el artículo 116 de la CE no son institutos inmediatamente aplicables a partir de su enunciado constitucional. Dicho artículo regula formas y procedimientos, señala límites temporales y proclama, entre otras garantías, la indisolubilidad de las Cámaras bajo su vigencia, pero no identifica las situaciones excepcionales a las que cada estado debe hacer frente ni precisa los apoderamientos extraordinarios a que pueden dar lugar. «Una ley orgánica regulará los estados de alarma, de excepción y de sitio, y las competencias y limitaciones correspondientes», proclama el artículo 116.1 de la CE, convirtiendo esa regulación en pieza necesaria y fundamental del sistema de fuentes del derecho español de excepción, por cuanto dicha ley debía ser la que definiera la naturaleza de los estados, los supuestos declarativos y las medidas extraordinarias a adoptar.

No faltaban argumentos a favor de una concepción gradual de los tres estados como diversos estadios de intensidad creciente en función de la gravedad de la emergencia. En nuestro derecho histórico, las diversas leyes de orden público se habían adscrito a dicha concepción. Partidario de la gradualidad se mostró el Informe de la Ponencia constitucional, según el cual debían «recogerse [...] las tres situaciones excepcionales clásicas para graduar la mayor o menor intensidad de aquéllas»". Las garantías constitucionales que rodean la declaración de los estados de alarma, excepción y sitio reflejan, por su parte, un progresivo protagonismo del Congreso de los Diputados (art. 116.2, 3 y 4 CE). Y escalonado está, asimismo, el eventual efecto de los diversos estados sobre las garantías constitucionales (arts. 55.2 y 117.5 de la CE). Pese a ello, la Ley Orgánica 4/1981, de 1 de junio, de los estados de alarma, excepción y sitio (LOAES) se decantó por una «lectura pluralista» de nuestro derecho constitucional de excepción en la que los tres estados fueron configurados como instrumentos distintos para hacer frente a emergencias sustancialmente distintas: «el estado de alarma — subrayó el senador socialista Morán López- para unas situaciones que vienen de hechos naturales o sociales que ocurren en la historia; el estado de excepción para situaciones que afectan al orden público y que es previsible que no puedan atajarse por los medios ordinarios; y el estado de sitio ante procesos que afectan al orden constitucional $»^{10}$. Constitucionalmente, sin embargo, nada avalaba una opción tan rígida que prescindiera de un posible uso gradual de dichos estados. Al contrario.

En los debates constituyentes desarrollados en el seno de la Comisión de Asuntos Constitucionales del Congreso de los Diputados, el estado de alarma, concretamente, fue presentado como un instrumento para hacer frente a crisis o catástrofes desprovistas de toda connotación política, pero también como una suerte de primer grado de emergencia político-social que no requiriera, por su relativa menor gravedad, de una suspensión generalizada de derechos constitucionales. Su precedente, el

9 B.O.C. n. ${ }^{\circ} 82,17$ de abril de 1978 , p. 1574.

10 D.S.S. n. ${ }^{\circ} 105$, de 14 de mayo de 1981, p. 5312. 
estado de prevención regulado en la Ley de Orden Público de 1933, era precisamente eso: un primer grado de situación excepcional de orden público en el que determinados derechos podían ser sometidos a un régimen particularmente restrictivo que no alcanzaba, sin embargo, a suspenderlos. A fin de evitarlo, los diputados comunistas Solé Tura y Sánchez Montero presentaron enmiendas de supresión, «porque el estado de alarma, o se explica para circunstancias excepcionales, en casos de cataclismos o desastres naturales, en cuyo caso el Gobierno tiene poderes suficientes para hacerles frente o $[\ldots .$.$] puede ocurrir que ese estado sirva para limitar$ derechos sin decirlo» ${ }^{11}$. El ponente centrista, Cisneros Laborda, defendió en la Comisión el rechazo de dichas enmiendas, y sus argumentos revelaron con claridad la función que quería asignarse al estado de alarma y, a la postre, la naturaleza bifronte con que había sido concebido:

«[...] la aceptación de la enmienda del Sr. Solé Tura abocaría al resultado paradójico de que, para la consideración de problemas de menos entidad, para situaciones conflictivas menos graves, se seguirían consecuencias mucho más penosas, desde el punto de vista jurídico, al tener que recurrir a la declaración del estado de excepción con la suspensión de garantías que, en este caso, sí conlleva» ${ }^{12}$.

Ante el recelo del grupo comunista, al que se sumó el grupo socialista, de que se reeditara el llamado estado de prevención, los portavoces centristas aseguraron, sin embargo, en el debate celebrado en el Pleno del Congreso sobre el proyecto constitucional, que el estado de alarma iría dirigido a enfrentar, fundamentalmente, aquellas situaciones que pusieran en peligro la subsistencia física de la comunidad: «[...] el estado de alarma ahora introducido no es una figura política — subrayó el diputado Apostúa Palos—, es la forma de capacitar al Gobierno [...] para una rápida reacción ante catástrofes naturales o tecnológicas» ${ }^{13}$. Y la cuestión volvió a plantearse en el Senado, donde nuevamente se oyó una tesis y su contraria, de suerte que el dilema acerca de la consideración del estado de alarma como emergencia cualitativamente distinta, como primer estadio excepcional o como ambas cosas al tiempo, no quedó zanjado ${ }^{14}$. Dada la ambigüedad resultante, el artículo 20 del proyecto de ley orgánica de seguridad ciudadana - que precedió al proyecto de ley orgánica de los estados de alarma,

11 D.S.C.D. Comisión de Asuntos Constitucionales, n. ${ }^{\circ} 84,8$ de junio de 1978, p. 3074. También presentaron enmiendas de supresión al estado de alarma, pero "por carecer de contenido», los diputados de Alianza Popular, Fernández de la Mora y Riestra París.

12 Ibidem, pp. 3075.

13 D.S.C.D. Pleno, n. ${ }^{\circ}$ 109, 13 de julio de 1978, p. 4238.

14 La indefinición constitucional posibilitaba que el estado de alarma pudiera contemplarse como un instrumento «frente a catástrofes naturales, frente a ciertos tipos de conflictividad social que no exigieran la suspensión de garantías, e incluso frente a algún supuesto de conflictividad político-social». Cfr. F. FERNÁNDEZ SEGADO, «La Ley Orgánica de los estados de alarma, excepción y sitio», Revista de Derecho Político, n. ${ }^{\circ} 11$, 1981, p. 96. 
excepción y sitio $^{15}$ — pretendió hacer del estado de alarma un instrumento versátil que pudiera utilizarse para afrontar emergencias muy dispares, enunciadas a título meramente ejemplificativo («situaciones como las siguientes»), entre las que se incluían las catástrofes y calamidades naturales o tecnológicas, las crisis sanitarias y las situaciones de desabastecimiento de productos de primera necesidad, pero también la «paralización de los servicios públicos esenciales para la comunidad» y hasta las «alteraciones del orden público o de la seguridad ciudadana cuando su restablecimiento no se pueda conseguir mediante el uso de las potestades ordinarias de la autoridad gubernativa» ${ }^{16}$. En consonancia con ello, el artículo 28 del proyecto preveía la declaración del estado de excepción «cuando el orden público resultara tan gravemente alterado que el ejercicio de las potestades previstas en los artículos anteriores [relativos al estado de alarma] fuera insuficiente para restablecerlo o mantenerlo».

Tras la conversión del capítulo III del proyecto de ley orgánica de seguridad ciudadana en proyecto de ley orgánica de los estados de alarma, excepción y sitio, el Gobierno, en su defensa ante el Pleno del Congreso, justificó los supuestos de declaración del estado de alarma en «la necesidad de proteger la sociedad frente a una suma de riesgos donde, bien por producirse hechos naturales, bien por circunstancias sociales, se encuentra en grave peligro la seguridad o la vida de las personas $\gg^{17}$. Pero iniciada su tramitación parlamentaria, los cambios en la redacción de dicho estado y del de excepción se sucedieron con rapidez e incidieron sobre aspectos sustanciales del proyecto originario. El Informe de la Ponencia suprimió la mención a las crisis de orden público como supuesto habilitante del estado de alarma, incorporó al supuesto de paralización de servicios públicos esenciales la cautela de que hubieran fallado las garantías precisas para asegurar su mantenimiento a las que se refieren los artículos 28.2 y 37.2 de la CE y configuró el estado de excepción como una emergencia que cabe declarar cuando el ejercicio de las potestades ordinarias resulte insuficiente, sin previa declaración del estado de alarma. El Pleno de Congreso de los Diputados, por su parte, aprobó lo que sería la redacción definitiva del artículo 4 de la LOAES, en la que desapareció la cláusula abierta que enunciaba las situaciones que podían desencadenar la

15 El Gobierno remitió al Congreso de los Diputados en septiembre de 1979 un proyecto de ley orgánica de seguridad ciudadana en el que, además de las facultades ordinarias en materia de orden público, pretendían regularse los estados de alarma, excepción y sitio, los supuestos de suspensión individual previstos en el artículo 55.2 de la CE y el régimen jurídico de los Cuerpos y Fuerzas de Seguridad del Estado, dando con ello cumplimiento a diversos mandatos constitucionales. A instancias del grupo parlamentario comunista, la Ponencia propuso en su informe desglosar el contenido del citado proyecto en cuatro proyectos de ley diferentes, lo que fue ratificado por la Comisión Constitucional del Congreso. Tras el fallido golpe de Estado de 23 de febrero de 1981, el proyecto de ley orgánica de los estados de alarma, excepción y sitio fue tramitado por el procedimiento de urgencia.

16 B.O.C.G. Congreso de los Diputados, I Legislatura, Serie A, n. ${ }^{\circ}$ 73-I, 21 de septiembre de 1979.

17 Intervención del ministro del Interior, J.J. Rosón, en el D.S.C.D. Pleno, n. ${ }^{\circ} 160$, de 21 de abril de 1981 , p. 9876. 
declaración del estado de alarma y, tras aceptar una enmienda in voce del grupo parlamentario comunista, desnaturalizó el supuesto de paralización de servicios públicos esenciales al exigir que, simultáneamente, concurriera «alguna de las demás circunstancias contenidas en este artículo». Con ello, el legislador asumió la pretensión de la izquierda parlamentaria de depurar el estado de alarma de cualquier connotación política y social, pero el resultado de tantas restricciones en sus supuestos habilitantes fue la configuración de un estado excepcional sui generis de ambigua naturaleza.

\section{EL ESTADO DE ALARMA COMO INSTRUMENTO EXTRAORDINARIO FRENTE A CALAMIDADES NATURALES, CRISIS SANITARIAS Y EMERGENCIAS DE NATURALEZA SOCIAL. SU DECLARACIÓN EN DICIEMBRE DE 2010 Y MARZO DE 2020}

El Gobierno, en uso de las facultades que le otorga el artículo 116.2 de la CE, está facultado por el artículo 4 de la LOAES para declarar el estado de alarma cuando se produzcan «a) catástrofes, calamidades o desgracias públicas, tales como terremotos, inundaciones, incendios urbanos y forestales o accidentes de gran magnitud; b) crisis sanitarias, tales como epidemias y situaciones de contaminación graves; c) paralización de servicios públicos esenciales para la comunidad, cuando no se garantice lo dispuesto en los artículos 28.2 y 37.2 de la CE, y concurra alguna de las demás circunstancias o situaciones contenidas en este artículo; y d) situaciones de desabastecimiento de productos de primera necesidad». Al añadir al supuesto de paralización de servicios públicos esenciales la exigencia de que concurriera otra de las circunstancias citadas, el legislador convirtió dicho supuesto en una mera «situación agravante de cualquiera de las tres emergencias que el artículo 4 de la LOAES comprende: catástrofes, crisis sanitarias y desabastecimientos» ${ }^{18}$. O lo que es lo mismo, dejó de ser un presupuesto del estado de alarma, dado que su sola existencia, derivada de huelgas o conflictos colectivos ilegales, no bastaba para habilitar la declaración. Con ello, desaparecía supuestamente la naturaleza bifronte del estado de alarma y su funcionalidad quedaba, pretendidamente, limitada a las emergencias de origen natural. Pero, pese a este giro que quiso convertir dicho estado en un instrumento neutro, el legislador no pudo evitar en su regulación la lógica gradualista consustancial a los estados de menor gravedad constitucional ${ }^{19}$.

18 P. Cruz Villalón, «El nuevo derecho de excepción», REDC, n. ${ }^{\circ}$ 2, 1981, p. 98.

19 Como J. M. Serrano Alberca ha subrayado, «si bien existe una diferencia cualitativa entre los tres estados, esta diferencia no los convierte en compartimentos estancos, absolutamente diferentes, sino que todos están unidos por la excepcionalidad y entre ellos puede descubrirse un gradualismo que se [...] pone de manifiesto tanto por la interrelación de las situaciones como por las medidas empleadas - previstas - para contrarrestarlas». Cfr. «Comentario al artículo 116», en F. Garrido Falda (dir.), Comentarios a la Constitución, 3. ${ }^{a}$ Ed., Civitas, Madrid, 2001, p. 1776. 
Abundando en una lectura en clave de neutralidad político-social de los supuestos habilitantes, alguna doctrina situó el fundamento constitucional del estado de alarma en el artículo 30.4 de la CE, introducido en el Senado a propuesta del centrista Pérez Maura, por cuanto su declaración, «más que afectar al ejercicio de los derechos y libertades de los ciudadanos, afecta a los deberes de los mismos», que deben ser regulados por ley en casos «de grave riesgo, catástrofe o calamidad pública» según el referido precepto ${ }^{20}$. El alcance de los presupuestos de hecho del artículo 4 de la LOAES no sería otro, por tanto, que el de las circunstancias del artículo 30.4 de la $\mathrm{CE}$, lo que haría del estado de alarma una modalidad de protección civil reforzada en punto a sus medidas y más solemne en su declaración.

Otra doctrina ha rechazado, en cambio, esta interpretación y, atendiendo a la lógica del principio de necesidad, ha estimado que la relación de supuestos habilitantes del estado de alarma no debería considerarse taxativa y que su activación no puede limitarse a las catástrofes o calamidades naturales, para las que ya existe legislación especial aplicable, a riesgo de convertir este estado en un instrumento ineficaz. Las situaciones de paralización de servicios públicos esenciales para la comunidad y de desabastecimiento de productos de primera necesidad previstas en el artículo 4.c) y d) de la LOAES pueden ser consecuencia de crisis naturales, pero también del abuso de derechos de los trabajadores de dichos servicios o del incumplimiento de sus obligaciones. La letra d) del artículo 4 de la LOAES no excluye que las situaciones de desabastecimiento de productos tengan origen en un conflicto social, «en cuyo caso, si además se produce una paralización de servicios públicos esenciales, cabría extender a estos las medidas del estado de alarma» ${ }^{21}$. Las situaciones críticas enunciadas en el artículo 4 de la LOAES pueden tener, además, una relación causal entre ellas (calamidades públicas, crisis sanitarias o desabastecimiento de productos que sean resultado de una paralización de servicios esenciales, por ejemplo), lo que, unido a las medidas extraordinarias que es posible activar bajo este estado, especialmente la ocupación de industrias y locales y la movilización de su personal (arts. 11.c) y 12.2 de la LOAES), abonan la posibilidad de utilizar el estado de alarma como medio de afrontar supuestos de alteración o perturbación de la paz social ${ }^{22}$. El constituyente, ha señalado García Cuadrado abundando en esta tesis, pretendió configurar un estado de anomalía para hacer frente a catástrofes naturales, calamidades y crisis sanitarias, pero

20 J. Porres Azkona, «La decisión sobre poderes excepcionales», RVAP, n. ${ }^{\circ}$ 6, 1983, pp. 59-60; E. Alvarez Conde, Curso de Derecho Constitucional, vol. I, Tecnos, Madrid, 1992, p. 434, y J. M. ${ }^{a}$ Lafuente Balle, «Los estados de alarma, excepción y sitio (II)», Revista de Derecho Político, n. ${ }^{\circ} 31,1990$, p. 30.

21 P. Cruz Villalón, Estados excepcionales y suspensión de garantías, cit., pp. 70-71.

22 En este sentido, F. Fernández SEgado, «La Ley Orgánica de los estados de alarma, excepción y sitio», cit., p. 95, y J. M. Goig MarTínez, «La defensa política de la Constitución. Constitución y estados excepcionales. (II) Un estudio de derecho constitucional comparado», Revista de Derecho UNED, n. ${ }^{\circ}$ 5, 2009, p. 225, para quien el estado de alarma «responde a la doble necesidad de construir un instrumento frente a catástrofes naturales y situaciones de anormalidad social [...] que perturben el normal desenvolvimiento de la vida social del país». 
«quiso dejar abierta la puerta a una concentración excepcional de poder y al uso de potestades exorbitantes por el gobierno cuando se produjeran alteraciones menos graves del orden público o social que pudieran resolverse sin necesidad de recurrir a la suspensión de derechos constitucionales» ${ }^{23}$. $\mathrm{Y}$ es en ese ámbito, tanto o más que en el característico de la protección civil frente a incendios o inundaciones para los que la legislación ordinaria ya prevé apoderamientos específicos, donde, a juicio de esta doctrina, el estado de alarma podría desempeñar su funcionalidad excepcional.

Durante décadas, ninguna situación de las enunciadas en el artículo 4 de la LOAES desencadenó la aplicación del estado de alarma. Graves incendios forestales, terremotos, inundaciones y enfermedades contagiosas fueron situaciones críticas afrontadas por las autoridades con las medidas previstas en la Ley 2/1985, de 21 de enero, de Protección Civil y en otras leyes sectoriales (entre ellas, la Ley 81/1968, de 5 de diciembre, de Incendios Forestales; la Ley Orgánica 3/1986, de 14 de abril, de Medidas Especiales en Materia de Salud Pública; la Ley 33/2011, de 4 de octubre, General de Salud Pública, etc.), así como en el artículo 15.3 de la Ley Orgánica 5/2005, de 17 de noviembre, de la Defensa Nacional y el Protocolo de intervención de la Unidad Militar de Emergencias (UME), aprobado por Real Decreto 1097/2011, de 22 de julio. Los supuestos habilitantes de las letras a) y b) del artículo 4 de la LOAES concurrieron en numerosas ocasiones, pero el estado de alarma quedó inédito. Y, pese a la declaración de estados similares en otros países europeos, la opinión doctrinal dominante lo consideraba un recurso excepcional inútil que había sido vaciado de contenido por la legislación sectorial establecida para tiempos de normalidad ${ }^{24}$.

23 «En la mente del constituyente — subraya el autor - se encontraban aquellas situaciones ocasionadas por culpa de la actuación del hombre, cuando el abuso irracional del derecho de huelga o actuaciones ilegales generalizadas, tales como ciertas huelgas de transportes, de panaderos, de comerciantes de la alimentación, de personal sanitario, de recogida de basuras y otras similares, en las que no se respetasen los servicios mínimos decretados por el Gobierno, pudiese ocasionar graves daños a la sociedad. La conflictividad social podrá afectar sólo a sectores muy minoritarios — por lo que no sería necesaria la declaración del estado de excepción-y, sin embargo, las consecuencias podrían ser gravísimas para el conjunto de la sociedad, por lo que no sería suficiente con aplicar las normas legales sobre protección civil en caso de calamidad; sobre todo porque éstas presuponen la voluntaria colaboración social y el supuesto imaginado parte de todo lo contrario. De manera que, ante la dualidad catástrofe natural-conflictos político sociales, es posible que el constituyente mayoritario pensase en situaciones que participaran a un tiempo de ambas cosas». A. M. GARCía CUADRADO, «El estado de alarma y su ambigua naturaleza», Cuadernos Constitucionales de la Cátedra Fadrique Furió Ceriol, n. ${ }^{\circ} 8,1994$, p. 85 .

24 P. Cruz Villalón, Estados excepcionales y suspensión de garantías, cit., p. 70. Asimismo, R. MateuRos y CEREzo, para quien « [el] arsenal de disposiciones que contemplan las más variadas situaciones de emergencia administrativa sin necesidad de los requisitos que supone la declaración del estado de alarma, ha vaciado este último de contenido propio, excepto en relación con aquellos fenómenos que, siendo inscribibles en la relación de presupuestos materiales que antes veíamos, carezcan de reglamentación especial. Obsérvese, además, que la técnica del decreto-ley permite al Ejecutivo adoptar ante situaciones de esta naturaleza las medidas de urgencia que requieran rango legal sin necesidad tampoco de acudir al estado de alarma (como ocurrió en las inundaciones de Valencia de octubre de 1982)». Cfr. «Estados de alarma, excepción y sitio», en VV. AA., Gobierno y Administración en la Constitución, vol. I, IEF, Madrid, 1988, pp. 175-176. 
En diciembre de 2010 y marzo de 2020, sin embargo, la realidad excepcional, inaprensible e imprevisible jurídicamente, se encargó de evidenciar lo errónea que era esta tesis, haciendo necesaria la declaración de sendos estados de alarma para enfrentar, respectivamente, los efectos de una «huelga salvaje» que saboteó el transporte aéreo y la gravísima emergencia de salud pública ocasionada por la pandemia global de la COVID-19. Pero la concurrencia de ambas situaciones excepcionales también evidenció la naturaleza bifronte del estado de alarma y su versatilidad como instrumento útil ante emergencias naturales y crisis sanitarias graves, así como frente a determinados conflictos sociales que no requieren la suspensión generalizada de derechos.

Tras meses de tensas negociaciones entre los controladores civiles de tránsito aéreo al servicio de la entidad pública empresarial Aeropuertos Españoles y Navegación Aérea (AENA), dicha empresa y el Ministerio de Fomento, el Gobierno aprobó el Real Decreto-ley 13/2010, de 3 de diciembre, cuya disposición adicional segunda ratificaba la jornada laboral aprobada en el Decreto 1001/2010, de 5 de agosto, y apelaba a AENA para facilitar lo dispuesto en el artículo 4.4.a) de la Ley 21/2003, de 7 de julio, de Seguridad Aérea ${ }^{25}$. Esa misma tarde, cientos de controladores abandonaron de forma concertada sus puestos de trabajo, alegando el supuesto de incapacidad psicológica previsto en la propia Ley de Seguridad Aérea. Ante esta situación, el Gobierno encomendó al jefe del Estado Mayor del Ejército del Aire las facultades de control de tránsito aéreo atribuidas a AENA, en una suerte de «militarización» operativa del servicio que no surtió efecto debido a la imposibilidad de la autoridad militar para impartir órdenes de obligado cumplimiento a los controladores civiles. A resultas de su abandono masivo del servicio, el espacio aéreo español fue cerrado, cientos de vuelos fueron suspendidos y miles de viajeros se vieron afectados. El Gobierno decidió entonces declarar el estado de alarma mediante el Real Decreto 1673/2010, de 4 de diciembre [BOE n. ${ }^{\circ} 295$, de 4 de diciembre (extraordinario)], cuyo artículo 3 atribuyó a los controladores la consideración de personal militar a los efectos de lo previsto en el artículo 10 de la LOAES, quedando sometidos a las órdenes de las autoridades militares y a las leyes penales y disciplinarias militares, de conformidad con el artículo 8 de la Ley Orgánica 13/1985, de 9 de diciembre, de Código Penal Militar. En apenas unas horas, la normalidad volvió a las torres y los centros de control, recuperándose tanto la maltrecha salud psíquica de los controladores como el servicio aeroportuario. La declaración del estado de alarma y la medida de la militarización suscitaron críticas por parte de la doctrina, pero, «vistos los resultados, — ha subrayado Requejo Rodríguez- es incuestionable la eficacia de la declaración ya que una vez tuvo lugar los controladores fueron requeridos para

25 Sobre el origen y evolución del conflicto laboral, C. Vidal Prado y D. Delgado Ramos, «Algunas consideraciones sobre la declaración del estado de alarma y su prórroga», REDC, n. ${ }^{\circ}$ 92, 2011, pp. $243-247$. 
que volvieran a sus puestos y así lo hicieron bajo mando y vigilancia militar» ${ }^{26}, \mathrm{y}$ sin necesidad de aplicar las citadas leyes militares.

Absolutamente imprescindible fue también la declaración del estado de alarma el 14 de marzo de 2020, tres días después de que la Organización Mundial de la Salud (OMS) calificara el brote de coronavirus COVID-19 de pandemia global y alertara de su imparable propagación internacional. En las semanas siguientes, España se enfrentó a una crisis sanitaria sin precedentes y de enorme magnitud, que provocó miles de muertos y a punto estuvo de colapsar el sistema sanitario. Para proteger la salud y la seguridad de los ciudadanos, contener la progresión de la enfermedad y reforzar el sistema de salud pública, el Gobierno dictó el Real Decreto 463/2020, de 14 de marzo (BOE n. ${ }^{\circ} 67$, de 14 de marzo), modificado por el Real Decreto 465/2020, de 17 de marzo (BOE n. ${ }^{\circ} 73$, de 18 de marzo) de acuerdo con la habilitación contenida en la disposición final 2. ${ }^{a}$ de aquel, y, tras obtener las correspondientes autorizaciones parlamentarias, aprobó sucesivos decretos de prórroga ${ }^{27}$, en los que restringió sensiblemente la libertad de circulación de las personas por las vías de uso público, sometió a los cuerpos y fuerzas de seguridad del Estado, los cuerpos de policía de las CCAA y de las corporaciones locales y a la seguridad privada a la autoridad del ministro del Interior, movilizó a las Fuerzas Armadas, autorizó requisas temporales y adoptó una amplia batería de medidas para reforzar el Sistema Nacional de Salud, asegurar el suministro de bienes y servicios necesarios para la protección de la salud pública, evitar el desabastecimiento alimentario y limitar el trasporte interior y el trasporte aéreo a los servicios mínimos esenciales compatibles con las exigencias de salud pública ${ }^{28}$.

Transcurridas seis semanas de la declaración, el índice de transmisión comunitaria del virus redujo su crecimiento diario del $42 \%$ a menos del $1 \%$ y el número básico de reproducción epidémica $\left(\mathrm{R}_{0}\right)$, o promedio de infectados secundarios que genera un solo infectado, descendió de 4,33 a 0,65 a primeros de mayo. Paralelamente, disminuyeron los casos confirmados diarios por PCR, los ingresos hospitalarios y en UCI y los fallecimientos por coronavirus ${ }^{29}$, lo que

26 P. Requejo Rodríguez, «Teoría vs. práctica del estado de alarma en España», VV. AA. Constitución y democracia: ayer y hoy. Libro homenaje a Antonio Torres del Moral, vol. 2, Universitas, Madrid, 2012, pp. 1505.

27 Las sucesivas prórrogas se formalizaron mediante los R.R.D.D. 476/2020, 487/2020, 492/2020, $514 / 2020,537 / 2020$ y 555/2020.

28 La declaración del estado de alarma dio cobertura jurídica, asimismo, a las medidas adoptadas por algunas CCAA, sin la cual resultaban de muy dudosa constitucionalidad: concretamente, la Orden de la Consejería de Salud de Murcia de 12 de marzo de 2020, la Resolución INT/718/2020, de 12 de marzo de la Generalitat de Cataluña, o las órdenes de 13 de marzo de las Consejerías de Salud y de Seguridad dictadas en el País Vasco que implicaron el confinamiento de centenares de miles de personas en diferentes municipios. Sobre estas medidas, L. Cotino Hueso, «Confinamientos, libertad de circulación y personal, prohibición de reuniones y actividades y otras restricciones de derechos por la pandemia del Coronavirus», Diario La Ley, n. ${ }^{\circ} 9608,6.04 .2020$, p. 5.

29 Ministerio de Sanidad (Centro de Coordinación de Alertas y Emergencias Sanitarias), Información cientifico-técnica. Enfermedad por coronavirus COVID-19, actualización n. ${ }^{\circ} 106,15$ de mayo 2020. 
llevó al propio Tribunal Constitucional (TC), requerido a pronunciarse en amparo sobre la afección del derecho de reunión, a reconocer que «las medidas de distanciamiento social, confinamiento domiciliario y limitación extrema de los contactos y actividades grupales impuestas bajo el estado de alarma» se habían «adverado eficaces para limitar los efectos de una pandemia de dimensiones desconocidas hasta la fecha» (ATC 40/2020, de 30 de abril, FJ 4).

\section{EL CUESTIONAMIENTO DE LOS ESTADOS DE ALARMA DECLARADOS EN 2010 Y 2020 Y LA FALSA DISYUNTIVA ENTRE LA DECLARACIÓN DE ALARMA O DE EXCEPCIÓN}

Tras su declaración en 2010 y 2020, el estado de alarma tuvo ocasión de acreditar su funcionalidad para normalizar el funcionamiento de un servicio público esencial y para superar una enorme crisis sanitaria. En ambos casos, sin embargo, su declaración suscitó abundantes críticas. En el primero, porque, según adujeron los afectados y parte de la doctrina, no concurrieron los supuestos legales para su declaración y la militarización suspendió varios derechos fundamentales de los controladores aéreos. En el segundo, porque la severísima restricción de la libertad de circulación, el confinamiento impuesto, la prohibición de actividades grupales y el cierre de fronteras habrían excedido, supuestamente, las medidas susceptibles de adoptar bajo el estado de alarma. Y en las dos ocasiones, de tan distinta naturaleza, se desató la polémica sobre si, en lugar de declararse el estado de alarma, debía haberse declarado el estado de excepción.

Inicialmente, la declaración del estado de alarma para enfrentar la crisis sanitaria provocada por la COVID-19 fue considerada adecuada, al encajar con claridad en uno de los supuestos habilitantes de este estado, contenido en el artículo 4.b) de la LOAES, y no hacerlo en absoluto entre las graves alteraciones de orden público que justifican un estado de excepción ${ }^{30}$. Pero a la vista del alcance y de la intensidad de la restricción de la libertad de movimientos, comenzó a hablarse de una alarma «excepcional» y de un «estado de excepción encubierto» ${ }^{31}$. Aragón Reyes afirmó que la LOAES no permite «decretar, como se ha hecho, la suspensión generalizada del derecho de libertad de circulación y residencia de los españoles, medida que solo puede adoptarse en el estado de excepción» ${ }^{32}$. Nogueira López sostuvo que las suspensiones generales de derechos para todo el territorio y toda la población con tan pocas excepciones como las previstas en el artículo 7 del

30 Por todos, J. Tajadura Tejada, «Derecho de crisis y Constitución», El País, 20 de marzo de 2020, y V. Álvarez GARCÍA, «El coronavirus (COVID-19): respuestas jurídicas frente a una situación de emergencia sanitaria», El Cronista del Estado Social y Democrático de Derecho, n. ${ }^{\circ} 86-87,2020$, pp. 15-21.

31 A. Cuenca Miranda, «Alarma excepcional», Papeles FAES, n. ${ }^{\circ} 236,2020$, pp. 3-6 y J. Albar GARcía, «Estado de excepción encubierto», El español, 18 de abril de 2020.

32 M. Aragón Reyes, «Hay que tomarse en serio la Constitución», El País, 10.04.2020. 
Decreto de declaración encajan entre las medidas del estado de excepción, no en el estado de alarma ${ }^{33}$. Amoedo-Souto denunció la «inconsistencia constitucional» de esta respuesta a la COVID-19, pues el confinamiento generalizado no es una simple limitación o compresión del ejercicio de los derechos de circulación y reunión «en determinados lugares, momentos o espacios públicos, sino una suspensión general de los mismos; suspensión que habría obligado como requisito previo a la declaración del estado de excepción $»^{34}$. Por su parte, Díaz Revorio sostuvo que la situación había alcanzado tal gravedad que podían considerarse cumplidos, al menos, dos de los supuestos de hecho que permiten la declaración del estado de excepción, al hallarse el servicio público sanitario desbordado y verse gravemente alterado el ejercicio de los derechos y libertades para evitar que el contagio de la epidemia provocara un caos mayor ${ }^{35}$. Y, en la misma línea, la sala de lo contencioso-administrativo del TSJ de Aragón, al tiempo que anulaba la prohibición de la Delegación del Gobierno de una manifestación en vehículos para conmemorar el 1 de mayo, afirmó inopinadamente lo siguiente: «[c]abe plantearse de manera más que razonable que una situación de crisis sanitaria como la que sufrimos en estos momentos puede implicar de facto una tan grave alteración del libre ejercicio de los derechos y libertades de los ciudadanos, o del normal funcionamiento de las instituciones, que haga razonable pensar que la herramienta más adecuada para el restablecimiento de tal normalidad de ejercicio pueda ser el estado de excepción [.... Y. Y ello por encima de una tesis meramente nominalista - desacertada en su elección a nuestro juicio de haber sido tal el único criterio para ello-, que asocia el estado de alarma como herramienta indicada para el tratamiento de este tipo de situaciones, con idéntico propósito de vuelta a la normalidad, sin plantearse que la elección de la herramienta pueda tal vez exigir su acomodación a la envergadura de la crisis, previo examen de la misma» (STSJ AR 224/2020, 28 de abril, fundamento de derecho 3..$^{\circ}$ ).

La mayoría de la doctrina, sin embargo, ha rechazado de plano que durante la crisis sanitaria ocasionada por la COVID-19 hayan concurrido los supuestos de hecho del estado de excepción, porque las potestades ordinarias a las que se refiere el artículo 13 de la LOAES no fueron «insuficientes para mantener el orden público» y éste en ningún momento se vio gravemente amenazado. Sin duda, como señalaron Martínez Alarcón y Presno Linera, un estado de alarma podría desembocar, en determinados casos, en graves alteraciones de orden público que afectaran al libre ejercicio de los derechos y libertades o al normal funcionamiento de

33 A. Nogueira López, «Confinar el coronavirus. Entre el viejo derecho sectorial y el derecho de excepción», El Cronista del Estado Social y Democrático de Derecho, n. ${ }^{\circ}$ 86-87, 2020, p. 27.

34 C. A. Amoedo-Souto, «Vigilar y castigar el confinamiento forzoso. Problemas de la potestad sancionadora al servicio del estado de alarma sanitaria», El Cronista del Estado Social y Democrático de Derecho, n. ${ }^{\circ} 86-87,2020$, p. 66.

35 F. J. Díaz Revorio, «A vueltas con la suspensión de los derechos fundamentales», Almacén de derecho, 9.04.2020. 
los servicios públicos esenciales, pero dichas alteraciones no se dieron el 14 de marzo, ni semanas después ${ }^{36}$. En el caso de la pandemia de la COVID-19, afirmó Marc Carrillo, «el orden público no ha sido alterado ni impedido el funcionamiento de las instituciones. La alteración producida ha sido de naturaleza distinta y ha afectado al sistema sanitario del país y a la salud de las personas. Éste ha sido el único orden alterado y no otro» ${ }^{37}$. La patente restricción resultante en el ejercicio de algunos derechos fundamentales hizo dudar de la idoneidad del estado de alarma, pero, como subrayó Cruz Villalón, «el estado de excepción, tal como nuestro ordenamiento lo configura, es expresión y respuesta a un conflicto político abierto. Sería concebible un estado de excepción superpuesto al de alarma en una situación de amplio desafío a este último, pero esto en modo alguno ha ocurrido, de tal modo que sería incluso injusto revestir con los caracteres de una emergencia de orden público unas medidas tan generalmente acatadas por la población $»^{38}$.

Idéntico dilema suscitó diez años antes la crisis provocada por los controladores aéreos, pero, en aquella ocasión, la práctica totalidad de la doctrina censuró la declaración del estado de alarma porque, de acuerdo con una interpretación literal de la letra c) del artículo 4 de la LOAES, la paralización del servicio esencial de transporte aéreo no era causa por sí misma para declarar el estado de alarma sin la concurrencia de alguna de las otras circunstancias previstas en las letras a), b) o c) del mismo artículo. En otros términos, que el boicot de los controladores no habilitaba la declaración.

En la exposición de motivos de la declaración del estado de alarma de 4 de diciembre de 2010, el Gobierno presentó la paralización del transporte aéreo provocada por los controladores como «una calamidad pública de enorme magnitud por el muy elevado número de ciudadanos afectados, la entidad de los derechos conculcados y la gravedad de los perjuicios causados». Pero, para la mayoría de la doctrina, esa calamidad pública nada tenía que ver con las catástrofes o desgracias naturales que enumera la letra a) del artículo 4 de la LOAES, ni con los desabastecimientos de productos previstos en su letra d), por lo que dicha doctrina concluyó que la declaración del estado de alarma fue ilegal ${ }^{39}$. Conforme a la literalidad

36 M. a L. Martínez Alarcón, «¿Es el estado de alarma en España un estado de excepción encubierto?», The conversation, 30 de marzo de 2020 y M. A. Presno LinerA, «Estado de alarma y sociedad del riesgo global», en E. Atienza Macías y J. F. Rodríguez Ayuso (dirs.), Las respuestas del Derecho a las crisis de salud pública, Dykinson, Madrid, 2020, p. 24.

37 M. Carrillo, «Los derechos en tiempo de pandemia», Al revés y al derecho, 17 de mayo de 2020.

38 P. Cruz Villalón, «La Constitución bajo el estado de alarma», El País, 17.04.2020. En el mismo sentido, J. M. ${ }^{a}$ CASTEllà ANDreu, «Incidencia de la Covid-19 sobre la democracia constitucional: reflexiones desde España», Letras Libres, 15.042020, D. López GARRIDO, «Un estado de excepción sería inconstitucional», Eldiario.es, 11.042020 y A. Rallo LOMBARTE, «Estado de alarma versus estado de excepción: una polémica estéril», Eldiario.es, 27 de abril de 2020.

39 C. Vidal Prado, y D. Delgado Ramos, «Algunas consideraciones sobre la declaración del estado de alarma y su prórroga», cit., pp. 253-255; A. AвA CATOIRA, «El estado de alarma en España», TRC, n. ${ }^{\circ} 28$, 2011, pp. 335-336; P. Requejo RodríGuez, «Teoría vs. práctica del estado de alarma en España», cit., pp. 1502-1503; A. Sedano Lonenzo, El estado de alarma y la justicia militar. A propósito de la crisis de 
del precepto, pocas dudas cabía albergar al respecto. El problema de esta interpretación de los supuestos habilitantes del estado de alarma es que conduce a una paradoja: la resultante de oponer la letra c) del artículo 4 de la LOAES a los principios de urgencia, necesidad y proporcionalidad que han de guiar la actuación del titular del poder de excepción. Veamos: atendiendo a la literalidad del precepto, la utilización del estado de alarma era ilegal, por lo que el Gobierno debería haber recurrido al estado de excepción, subrayó la mejor doctrina, para admitir a continuación que, tomando en consideración los referidos principios, la declaración del estado de excepción habría resultado improcedente. Evidentemente, la paradoja es irresoluble, y como no cabe sostener ambas premisas al tiempo, la doctrina ha asumido a la postre el acierto de utilizar el estado de alarma en lugar del estado de excepción. «[...] esta vía —afirman Vidal Prado y Delgado Ramos refiriéndose al estado de excepción — habría abierto todavía más incertidumbres, y hubiera sido muy complicada de tomar de modo urgente. Habría sido necesario convocar al Congreso de los Diputados el mismo sábado 4 de diciembre, lo cual habría retrasado todo el operativo de un modo que probablemente acabaría por hacer inútil la medida. Pero, además, se trataría ya de una declaración que llevaría consigo una suspensión de derechos, de mucha mayor gravedad; vía, además, de difícil defensa política y social, por lo que no parecía adecuado optar por ella» ${ }^{40}$. Y Sieira Mucientes señala que «la dilación temporal que en circunstancias normales supone convocar un Pleno y que este decida sobre todos estos extremos habría hecho inviable la declaración inmediata del estado de excepción, con el consiguiente daño irreparable para la normalidad constitucional y para la adecuada garantía de los derechos de los ciudadanos», admitiendo a continuación que el estado de alarma fue un expediente de cobertura de una actuación «necesariamente urgente e inaplazable al que el Gobierno ha podido acudir por la simplicidad de su procedimiento inicial con vistas a atajar una crisis constitucional que $[\ldots .$.$] no hubiera podido ser reconducida de otro modo, por su$ carácter apremiante, urgente, grave, y desde luego inaplazable» ${ }^{41}$.

En resumen: la urgencia, la necesidad y la proporcionalidad de la respuesta convirtieron la declaración del estado de alarma en la fórmula más adecuada para enfrentar la emergencia, aunque formalmente no procediera. ¿Asumimos entonces que necessitas legem non habet, como sostiene cierta doctrina ${ }^{42}$ ? En absoluto, porque, a nuestro juicio, una interpretación finalista de los supuestos legales del

controladores aéreos, Liber Factory, Madrid, 2015, pp. 80-84, y S. Siera MuCiEnTES, «Los estados excepcionales», RCG, n. ${ }^{\circ} 104,2018$, pp. 376-378.

40 C. Vidal Prado, y D. Delgado Ramos, «Algunas consideraciones sobre la declaración del estado de alarma y su prórroga», cit., p. 255.

41 S. Siera Mucientes, «Los estados excepcionales», cit., pp. 378 y 390.

42 El adagio necessitas legem non habet, reproducido en el Decretum Gratiani, que literalmente significa que «la necesidad no tiene ley», suele ser entendido en dos sentidos opuestos: «la necesidad no reconoce ley alguna» y «la necesidad crea su propia ley». En ambos casos, sostiene G. AgAmben, el derecho de excepción se disuelve íntegramente en la teoría del status necessitatis, de modo que el juicio sobre la concurrencia de la 
estado de alarma y el reconocimiento de la naturaleza constitucional bifronte de dicho estado pueden evitar la incómoda paradoja de un derecho de excepción doblegado por la excepción.

Las calamidades o desgracias públicas citadas en la letra a) del artículo 4 de la LOAES nada tienen que ver con la calamidad que supuso el boicot del tránsito aéreo, con la que el Gobierno justificó el estado de alarma, pero eso no convierte su declaración en inconstitucional. La enumeración abierta de circunstancias contenida en el proyecto de LOAES que habilitaban la declaración fue sustituida por una enumeración taxativa. Ello no impide, sin embargo, que puedan concurrir «otras situaciones calificables por su impacto objetivo y subjetivo de catástrofe o calamidad pública» que legitimen tanto o más que aquéllas el recurso al estado de alarma ${ }^{43}$. Y, al amparo de una interpretación finalista plenamente conforme, debería ser posible su declaración. El legislador anuló en la letra c) de la LOAES la paralización de servicios públicos esenciales como supuesto autónomo del estado de alarma, pero no excluyó que pudiera ser declarado cuando las situaciones de desabastecimiento de productos de la letra d) tuvieran origen en un conflicto social. Se incurrió, así, en una distinción bastante arbitraria entre «productos» y «servicios» en la medida en que la literalidad de la LOAES permite responder con el estado de alarma si faltan los primeros por causa de un conflicto laboral, pero no si fallan los segundos ${ }^{44}$. Imaginemos, por otra parte, que el cierre del espacio aéreo es consecuencia de la nube piroclástica provocada por una gran erupción volcánica. En ese caso, no existiría duda acerca de la procedencia de la declaración del estado de alarma. ¿Por qué negar, entonces, su procedencia si el mismo cierre del espacio aéreo es provocado por un boicot? Carece de sentido permitir al Gobierno declarar la alarma si hay una erupción volcánica que impide el tráfico aéreo - medida que de poco serviría puesto que la superación de la emergencia no depende de la acción gubernamental - y considerar en cambio ilegal la declaración de dicho estado tras el abandono de los controladores de sus puestos y precisamente para obligarles a incorporarse, para lo que sí sería eficaz. Aducir que la literalidad del artículo 4 LOAES impide recurrir al estado de alarma, implica abocar al Gobierno a solicitar autorización para un estado de excepción, con la demora correspondiente y la mayor gravedad jurídico-política de dicho estado, en el que se posibilita la suspensión general de derechos fundamentales. Así las cosas, el sabotaje se habría prolongado mientras el Estado permanecía inerme y el derecho de libre circulación era conculcado.

necesidad agota el problema de la legitimidad de aquél. Y en ello reside, precisamente, a su juicio, la paradoja del derecho de excepción. Cfr. Estado de excepción, cit., pp. 60-62.

43 Se plantea la hipótesis P. Requejo Rodríguez, «Teoría vs. práctica del estado de alarma en España», cit., p. 1502. La asumen plenamente, F. DE CARreras, «Un claro supuesto del estado de alarma», La Vanguardia, 5 de diciembre de 2010, y F. Balaguer Callejón, «El colectivo Eyjafjalla», Público, 8 de diciembre de 2010.

44 P. Cruz Villalón, Estados excepcionales y suspensión de garantías, cit., pp. 70-71. 
«Alarma por el estado de alarma», declaró tener Blanco Valdés tras su declaración ${ }^{45}$, pero lo alarmante habría sido no declararlo, o declarar en su lugar, demasiado tarde, un innecesario estado de excepción. De lege ferenda, conviene sin duda que el legislador clarifique la operatividad del estado de alarma en relación con los supuestos de conflictividad político-social, pero, en tanto dicha clarificación llega, asumamos que estas situaciones pueden volver a producirse y que una interpretación del estado de alarma conforme a su naturaleza bifronte es constitucionalmente posible al amparo de los antecedentes constitucionales y de los principios de necesidad y proporcionalidad consustanciales al derecho de excepción ${ }^{46}$.

\section{ALCANCE Y LÍMITES DE LAS MEDIDAS EXTRAORDINARIAS A ADOPTAR. LA DISTINCIÓN ENTRE LIMITACIÓN Y SUSPENSIÓN DE DERECHOS}

La declaración del estado de alarma puede dar lugar a una importante concentración en el ejercicio de las competencias administrativas. Las autoridades civiles de la Administración Pública del territorio afectado, los miembros de los cuerpos de policía de las comunidades autónomas y de las corporaciones locales y los demás funcionarios y trabajadores a su servicio quedarían «bajo las órdenes directas de la autoridad competente» en cuanto fuera necesario para la protección de personas, bienes y lugares, quien podría imponerles servicios extraordinarios por su duración o por su naturaleza (art. 9.1 de la LOAES). De incumplir o resistirse a dichas órdenes, la autoridad competente está habilitada para suspender a los funcionarios en el ejercicio de sus cargos y para asumir las facultades de sus autoridades si el incumplimiento o la resistencia fuera responsabilidad suya (art. 10.2 y 3 de la LOAES).

En los supuestos a) y b) del artículo 4 (catástrofes, calamidades o desgracias públicas y crisis sanitarias), el artículo 12.1 de la LOAES permite la adopción de todas aquellas medidas «establecidas en las normas para la lucha contra las enfermedades infecciosas, la protección del medio ambiente, en materia de aguas y sobre incendios forestales» (en la actualidad, especialmente, las Leyes 3/1986, de

45 R. Blanco Valdés, «Alarma por el estado de alarma», La Voz de Galicia, 6 de diciembre 2010.

46 Nos hallaríamos, en estos casos, ante «emergencias constitucionales no regladas», o deficientemente regladas, pero en las que el derecho no desaparece si el titular del poder de excepción se rige por el principio democrático y los principios de necesidad y proporcionalidad. P. Fernández De CaSAdevante, La defensa de la Constitución. El derecho de emergencia constitucional y el artículo 55 CE, Thomson Reuters-Aranzadi, Cizur Menor, 2020, pp. 69-77. «La creciente complejidad — señaló por su parte J. M. ${ }^{a}$ Lafuente VALLE— de los presupuestos de crisis del Estado no puede ser recluida en un texto jurídico y esta es la razón por la que, producida la crisis, es más que previsible que los órganos del Estado actúen al margen de la norma y, sin embargo, será preciso justificar su actuación. Es en esta justificación de actuaciones parajurídicas en defensa del Estado democrático donde actúa la teoría de la fuerza mayor - por supuesto, sujeta a los requisitos de gravedad, respeto constitucional, proporcionalidad y justiciabilidad-y cobra mayor eficacia». Cfr. «Los estados de alarma, excepción y sitio (II)», cit., p. 67. 
14 de abril, de Medidas Especiales en Materia de Salud Pública y 33/2011, de 4 de octubre, General de Salud Pública; la Ley 34/2007, de 15 de noviembre, de Calidad del Aire y Protección de la Atmósfera; la Ley 26/2007, de 23 de octubre, de Responsabilidad Medioambiental; el Real Decreto Legislativo 1/2001, de 20 de julio, que aprobó el texto refundido de la Ley de Aguas; la Ley 41/2010, de 29 de diciembre, de Protección del Medio Marino, y la Ley 43/2003, de 21 de noviembre, de Montes). Y ello es una relación meramente enunciativa, porque el Gobierno también podría adoptar medidas y asumir potestades extraordinarias previstas en otras normas habilitantes y cuyo ejercicio no precisa previa declaración del estado de alarma: entre ellas, las que recogía la Ley 2/1985, de 21 de enero, de Protección Civil, y las que recoge actualmente la Ley 17/2015, de 9 de julio, del Sistema Nacional Protección Civil, que permite imponer deberes y prestaciones adicionales (art. 7 bis y ter), particularmente en los casos de emergencia de interés nacional, entre los que se cita la declaración de los estados excepcionales (art. 28), y también, entre otras, las medidas y potestades que incorpora la Ley $36 / 2015$, de 28 de septiembre, de Seguridad Nacional en relación con la gestión de las situaciones de interés para la seguridad nacional (arts. 22-29).

El contenido fundamental del estado de alarma está regulado en los artículos 11 y 12.2 de la LOAES), que facultan al titular de la declaración a establecer limitaciones a la libertad de circulación o de permanencia de personas o vehículos en lugares determinados, o condicionarlas al cumplimientos de ciertos requisitos; permitir la práctica de requisas temporales en todo tipo de bienes e imponer prestaciones obligatorias; limitar o racionar el uso de servicios o el consumo de productos de primera necesidad: autorizar la intervención y ocupación transitoria de industrias, fábricas, talleres, explotaciones o locales de cualquier naturaleza, con excepción de domicilios privados; impartir las órdenes necesarias para asegurar el abastecimiento de los mercados y el funcionamiento de los servicios de los centros de producción afectados por la crisis; y, en los supuestos previstos en las letras c) y d) del artículo 4 de la LOAES, acordar la intervención de empresas o servicios, así como la movilización de su personal, con el fin de asegurar su funcionamiento.

Varias de estas medidas pueden suponer un aumento de las obligaciones de los ciudadanos o incidir en el estatuto jurídico ordinario de algunos derechos, limitándolos severamente. Ello es posible, porque la declaración del estado de alarma es, pese a su formalización mediante decreto, un acto con rango y fuerza de ley que, como ha subrayado el Tribunal Constitucional, tiene capacidad para «suspender o desplazar la aplicación de leyes, normas o disposiciones con rango de ley y para establecer restricciones o limitaciones en el ejercicio de derechos» (STC 83/2016, de 28 de abril, FJ 8) ${ }^{47}$. Las limitaciones no pueden implicar, sin

47 Sobre el rango y la fuerza de ley de los decretos de declaración y prórroga del estado de alarma, C. GARRIDO LóPEZ, «Naturaleza jurídica y control jurisdiccional de las decisiones constitucionales de excepción», REDC, n. ${ }^{\circ} 110,2017$, pp. 43-73. 
embargo, suspensión de derechos, sino, como señaló Cruz Villalón, un tercer estado de los derechos fundamentales que no es el de su plena vigencia, pero tampoco el de la anulación de su contenido esencial que supone la suspensión y cercena su habitual función de garantía ${ }^{48}$. Suspender un derecho, afirma Bastida Freijedo, «es excluirlo temporalmente del catálogo de derechos de la Constitución y desde ese momento sólo existirá en los términos y garantías que señale el decreto que lo suspende. Dicho en otras palabras, con la suspensión el derecho fundamental desaparece y, si vuelve a nacer, es como un derecho no fundamental, delimitado en los términos y con el alcance dispuestos en el decreto declarativo del estado de excepción (o de sitio)» ${ }^{49}$. Formalmente, sostuvo Aláez Corral, la suspensión conlleva una «desconstitucionalización» que deja sin efecto parcial o totalmente la obligatoriedad jurídica de un derecho fundamental. «La suspensión a que hace referencia el artículo 55.1 CE —afirmó - ha de ser entendida en un sentido estricto, y además formal, como la temporal supresión de la vigencia de las normas constitucionales sobre determinados derechos fundamentales, [...] cuyo régimen jurídico pasa a estar compuesto por las disposiciones de la LOAES, las previsiones de la declaración del estado de excepción o de sitio que la establecen, y cualesquiera otras disposiciones legales de desarrollo que no se vieran desplazadas en su aplicación por las anteriores $»^{50}$. La limitación de un derecho, en cambio, incide sobre su haz de facultades y puede llegar a la «negación transitoria del ejercicio del derecho a su titular», en palabras de Requejo Rodríguez, pero no lo desconstitucionaliza, ni priva al derecho de la garantía de su contenido esencial, que puede verse afectado por la limitación, pero no hasta el punto de provocar su completa desaparición ${ }^{51}$. En la limitación, las garantías normativas del derecho siguen intactas y los abusos pueden ser revisados judicialmente al amparo del principio de proporcionalidad, porque su régimen jurídico no ha sido desplazado ni suspendido. De estarlo, no sería posible violarlos ni recabar su posterior tutela sino en los términos que su nuevo régimen jurídico establezca. Un derecho suspendido no pone límites de proporcionalidad a la declaración del estado, ni a la autoridad gubernativa, pero sí lo hace un derecho limitado. La limitación, en fin, es una constricción en el ejercicio del derecho, no en su regulación.

En teoría, la delimitación es posible, pero el problema es que, en la práctica, resulta difícil distinguir dónde termina la limitación o restricción de derechos, lícita y proporcionada a las circunstancias bajo el estado de alarma, y dónde empieza una suspensión constitucionalmente reservada a los estados de excepción y sitio. Y el problema es especialmente delicado en el caso de las medidas extraordinarias de

48 P. CruZ Villalón, Estados excepcionales y suspensión de garantías, cit., p. 76.

49 F. Bastida Freijedo, «La cuarentena de los derechos», La Nueva España, 9 de abril de 2020.

50 B. AlÁEZ CORRAL, «El concepto de suspensión general de los derechos fundamentales», en L. López Guerra y E. Espín Templado (coords.), La defensa del Estado, Tirant lo Blanch, Valencia, 2004, p. 235.

51 P. Requejo Rodríguez, «¿Suspensión o supresión de los derechos fundamentales?», RDP, n. ${ }^{\circ} 51$, 2001, p. 112-113. 
limitación de la libertad de circulación, de intervención de empresas y servicios y de movilización de su personal que autorizan los artículos 11.a) y 12.2 de la LOAES, porque las tres previsiones evidencian la delgada línea que puede existir entre la limitación y la suspensión de derechos en el estado de alarma.

\section{LA MILITARIZACIÓN DE LOS CONTROLADORES DE TRÁNSITO AÉREO BAJO EL ESTADO DE ALARMA DE 2010}

El artículo 12.2 de la LOAES permite acordar, en los supuestos de las letras c) y d) del artículo 4 de la LOAES, la medida de movilización del personal de empresas y servicios, siendo de aplicación al personal movilizado la normativa vigente sobre movilización con carácter supletorio. Dicha movilización puede ser útil en diversas emergencias, pero fue más bien concebida para enfrentar conflictos de naturaleza u origen social, como los que el proyecto de ley orgánica de seguridad ciudadana de 1979 incluía antes de que la paralización de los servicios públicos esenciales dejara de ser un supuesto autónomo de declaración del estado de alarma. De esa circunstancia deriva precisamente alguno sus problemas. Y es que, más allá de su utilidad, la medida de movilización del personal de empresas y servicios puede conllevar, dependiendo de cuál sea la regulación a la que el artículo 12.2 de la LOAES remite en blanco, la afección del derecho de huelga y la extensión de la legislación militar al personal civil.

Durante décadas, la normativa aplicable a este supuesto fue la Ley 50/1969, de 26 de abril, Básica de Movilización Nacional, que militarizaba ficticiamente a los trabajadores movilizados sometiéndoles a las leyes penales militares y a la jurisdicción castrense (art. 18). La Ley 50/1969 fue aplicada en reiteradas ocasiones antes de la aprobación de la CE, pero también después de ella, en supuestos en que se incumplió la normativa de huelga con anterioridad a la aprobación de la LOAES: en marzo de 1979, se aplicó a los trabajadores de Unión Eléctrica de Canarias y al metro de Barcelona, y en agosto de 1979, a la empresa CAMPSA. La Ley Básica de Movilización Nacional perdió su rango, pero siguió vigente con carácter reglamentario en virtud de la disposición derogatoria única, apartado 2, de la Ley 17/1999, de 18 de mayo, de Régimen del Personal de las Fuerzas Armadas, aunque ya no fue aplicada. La Ley Orgánica 5/2005, de 17 de noviembre, de la Defensa Nacional la derogó parcialmente. Y quedó totalmente derogada por la Ley 39/2007, de 19 de noviembre, de la Carrera Militar, creándose, con ello, un vacío legal en punto a la medida de movilización prevista en el artículo 12.2 de la LOAES. La ausencia de normativa aplicable fue cubierta en la declaración del estado de alarma llevada a cabo en diciembre de 2010 por remisión al artículo 44 de la Ley 48/1960, de 21 de julio, de Navegación Aérea y al artículo 8.5 del Código Penal Militar, que consideraba militares a quienes «con cualquier asimilación militar presten servicio al ser movilizados o militarizados». Y al amparo de dichos preceptos, atribuyó a los controladores aéreos la consideración de 
personal militar, sometiéndolos a las órdenes directas de los mandos militares y a las leyes penales y disciplinarias militares.

A juicio de alguna doctrina, dicha movilización, convertida en militarización, implicó la suspensión del derecho de huelga de los controladores dado que, en el supuesto que hubiesen querido canalizar el conflicto por esa vía de conformidad con su normativa reguladora, su ejercicio habría sido delictivo al poseer esa consideración en el Código Penal Militar. Y de incumplir sus obligaciones, se habría extendido la jurisdicción militar fuera del ámbito estrictamente castrense y de los supuestos de estado de sitio, conculcando con ello el artículo 117.5 de la $\mathrm{CE}^{52}$. Para otra doctrina, sin embargo, el derecho de huelga no fue conculcado. Los controladores aéreos habían incurrido en una flagrante vulneración de derechos fundamentales de terceros por el incumplimiento intencionado de deberes y funciones. Su boicot había paralizado un servicio esencial ${ }^{53}$. Y para restablecerlo, el estado de alarma permite, incluso sin llegar a la movilización, imponer prestaciones obligatorias e impartir las órdenes necesarias para garantizar el funcionamiento de los servicios afectados (art. 11 LOAES), lo que supone la limitación temporal del derecho de huelga, cuyo ejercicio para sus titulares queda supeditado al restablecimiento del servicio, pero no suspendido ${ }^{54}$, porque sus garantías normativas y procesales continuaron intactas para los controladores, quienes pudieron recurrir ante la jurisdicción ordinaria y, en amparo, ante el Tribunal Constitucional ${ }^{55}$. Por motivos similares, tampoco compartimos la tesis de que la sumisión a la jurisdicción castrense fuera desproporcionada e inconstitucional. En opinión de José Jiménez Villarejo, expresidente de la Sala 5. ${ }^{a}$, de lo Militar, del Tribunal Supremo, que suscribimos, la movilización de los controladores debía ponerse en relación con el artículo 4 del Código Penal Militar, que preveía la sujeción a la jurisdicción militar no solo de los militares, sino también del personal movilizado o a quien un

52 En este sentido, C. Vidal Prado, y D. Delgado Ramos, «Algunas consideraciones sobre la declaración del estado de alarma y su prórroga», cit., pp. 255-260; P. REQUEJO RoDRíGueZ, «Teoría vs. práctica del estado de alarma en España», cit., pp. 1505-1506; A. SEDANo Lorenzo, El estado de alarma y la justicia militar. A propósito de la crisis de controladores aéreos, cit., pp. 106-129; S. SiERA MuCIENTES, «Los estados excepcionales», cit., p 380, y P. Fernández De CASADEVAnte, La defensa de la Constitución. El derecho de emergencia constitucional y el artículo 55 CE, cit., pp. 154-157.

53 El juzgado de lo Penal n. ${ }^{\circ} 18$ de Madrid, en su sentencia de 15 de octubre de 2020, ha condenado, por ello, a 131 controladores de los aeropuertos de Barajas y Torrejón por la comisión del delito de abandono colectivo de un servicio público tipificado en el artículo 409 del Código Penal.

54 M. ${ }^{a}$ D. Martínez Cuevas, «El estado de alarma y el derecho fundamental de huelga: el caso de los controladores civiles de tránsito aéreo en España», Trabajo y derecho, n. ${ }^{\circ}$ 64, 2020, p. 3.

55 Los controladores interpusieron varios recursos contencioso-administrativo por vulneración de derechos fundamentales ante la Sala 3. ${ }^{a}$ del Tribunal Supremo, que fueron inadmitidos por falta de jurisdicción (AATS 857/2011, 2985/2011, 3816/2011, 5696/2011 y 5698/2011, 6821/2011 y 6197/2012), y dos recursos de amparo: el primero contra la autorización parlamentaria de la prórroga del estado de alarma por vulneración de los mismo derechos, el segundo contra el ATS 5696/2011, por vulneración del derecho de acceso a la jurisdicción. Ambos fueron inadmitidos, porque, a juicio del Tribunal Constitucional, tanto las autorizaciones parlamentarias como los decretos de declaración y prórroga tienen naturaleza de actos del Estado con fuerza y valor de ley (ATC 7/2012, y STC 83/2016). 
precepto legal asimile, y con su artículo 8.5 que consideraba militares a quienes «con cualquier asimilación militar presten servicio al ser movilizados o militarizados a decisión del Gobierno». Por otra parte, el artículo 117.5 CE no determina el ámbito en el que actúa la jurisdicción militar, sino que se limita a señalar que dicho ámbito será determinado por la ley, lo que supone cierta libertad y flexibilidad para concretar mediante una ley el alcance de ese ámbito, sobre todo en situaciones excepcionales $^{56}$. Y esto es precisamente lo que se ha hecho. El fuero militar está reservado al estado de sitio y al ámbito estrictamente castrense determinado mediante ley, delimitación a la que procedió el artículo 4 del Código Penal Militar de 1985 y ha precisado el artículo 2.5 de la Ley Orgánica 14/2015, de 14 de octubre, que aprobó el nuevo Código Penal Militar, considerando militares a los efectos penales a quienes hayan sido movilizados al amparo de las previsiones de la LOAES, que se activan — no lo olvidemos - mediante actos con rango y fuerza de ley, lo que constituye, a nuestro juicio, un ámbito de militarización penal bastante estricto compatible con el artículo 117.5 de la CE y con su interpretación, contenida en la STC 75/1982 de 13 de diciembre (FJ 2).

\section{LA POLÉMICA SOBRE LA LIMITACIÓN O LA SUSPENSIÓN DE DERECHOS EN EL ESTADO DE ALARMA DECLARADO PARA GESTIONAR LA CRISIS SANITARIA DE LA COVID-19}

El dilema entre limitación y suspensión de derechos se ha vuelto a evidenciar con ocasión del estado de alarma declarado para gestionar la crisis sanitaria ocasionada por la COVID-19, en el que la prohibición generalizada de usar la vía pública, con algunas excepciones, o el cierre perimetral de la zona de la Conca d'Òdena (Barcelona) y de Arroyo de la Luz (Cáceres), fueron más allá, a juicio de alguna doctrina, de la mera limitación a «la circulación o permanencia de personas o vehículos en horas o lugares determinados» prevista en el artículo 11.a) de la LOAES, suspendiendo de facto la libertad deambulatoria y el derecho de reunión, entre otros derechos conexos, lo que debería haber llevado, según dicha doctrina, a la declaración de excepción y no a las sucesivas prórrogas de un estado como el de alarma que resultaba, debido a dicha suspensión, constitucionalmente inadecuado. «Ordenar una especie de arresto domiciliario de la inmensa mayoría de los españoles — señaló Aragón Reyes_ — [...] no es limitar el derecho, sino suspenderlo, y esa conclusión resulta difícilmente rebatible desde un entendimiento jurídico correcto» ${ }^{57}$. «Limitación de derechos habría sido — ha sostenido Teruel Lozanosi nos permitieran circular con condiciones - por ejemplo, usando mascarillas - o si hubiera un toque de queda a determinadas horas. Pero lo que se ha decretado es

56 J. Jiménez Villarejo, «La militarización de los controladores». El País, 13.12.2010.

57 M. Aragón Reyes, «Hay que tomarse en serio la Constitución», El País, 10.04.2020. 
una prohibición general de circular [...]. Y, como consecuencia, están prohibidas las reuniones (al menos presenciales) y las manifestaciones, y se ven seriamente comprometidas la libertad de culto y otros derechos fundamentales» ${ }^{58}$. El artículo 7 del Decreto 463/2020 habría afectado al contenido esencial del derecho a circular libremente por el territorio nacional sin tener naturaleza de ley orgánica y excediendo el contenido de la LOAES, por cuanto las limitaciones previstas convirtieron los derechos de libre circulación, reunión, manifestación y libertad de culto en absolutamente impracticables. En palabras de Díaz Revorio, «el decreto excluye a priori la posibilidad de que resulten satisfechos los intereses que protege la libertad de circulación, desfigurando el derecho hasta hacerlo no recognoscible. En definitiva, imposibilita la protección de las facultades en las que consiste la libertad de circulación, salvo en casos concretos muy tasados. Y con ello impide la prevalencia de la libertad de circulación en supuestos en los que esta tendría todo el sentido, desde la perspectiva de un examen de idoneidad-necesidad-proporcionalidad de sus restricciones» ${ }^{59}$.

Con estos argumentos, se presentaron tres recursos contencioso-administrativos contra los decretos de declaración y prórroga por el cauce especial de protección de los derechos fundamentales de la persona, pero fueron rechazados por unidad de doctrina en los AATS 2478/2020, de 4 de mayo, 2505/2020, de 6 de mayo, y 2508/2020, de 12 de mayo, al carecer el orden contencioso-administrativo de jurisdicción para enjuiciar actos con fuerza y valor de ley. Y similares argumentos ha incorporado el recurso de inconstitucionalidad n. ${ }^{\circ} 2054-2020$, presentado por los diputados del grupo parlamentario Vox contra los artículos 7 , 9, 10 y 11 del Decreto 463/2020, de 14 de marzo, y sus prórrogas, y la orden $\mathrm{SND} / 298 / 2020$, de 29 de marzo, que estableció medidas excepcionales en relación con los velatorios y ceremonias fúnebres. «El confinamiento impuesto en todo el territorio nacional y a la totalidad de la ciudadanía — se subraya en el recurso- , que debe permanecer recluida en su domicilio actual salvo razones justificadas de fuerza mayor o necesidad, constituye, por su rigidez e intensidad, una verdadera privación de libertad. Las personas físicas no podrán celebrar reuniones en sus propios domicilios [...] tampoco los profesionales podrán reunirse con sus clientes en lugares cerrados. Estas intensas restricciones no serían admisibles ni siquiera en los estados de excepción o de sitio; por lo que no puede haber ninguna discusión de su improcedencia en el estado de alarma decretado. [...] Los artículos 7 y 11 del Decreto 463/2020 suponen, además, una suspensión en toda regla de la dimensión externa de la libertad religiosa, contraria a la Constitución y al bloque de la constitucionalidad, al igual que la prohibición de los servicios religiosos

58 G. M. Teruel Lozano, «Control al Gobierno», El País, 8.04.2020.

59 F. J. Díaz Revorio, «A vueltas con la suspensión de los derechos fundamentales», cit.. En el mismo sentido, sin pretensión de exhaustividad, D. FernÁndez De GATTA SÁNCHEZ, «Los problemas de las medidas jurídicas contra el coronavirus: las dudas constitucionales sobre el estado de alarma y los excesos normativos», Diario La ley, n. ${ }^{\circ} 9634,18.05 .2020$. 
fúnebres contenida en la Orden SND/298/2020, al constituir estos una de las manifestaciones externas esenciales de dicha libertad ${ }^{60}$.

En sentido contrario, sin embargo, la mayoría de la doctrina ha considerado que la limitación de la libertad de circulación fue proporcionada y tuvo las suficientes excepciones como para considerarla una medida compatible con el régimen jurídico del estado de alarma, al igual que en otros países europeos que, como Italia, Portugal y Francia, adoptaron idénticas medidas restrictivas con figuras similares ${ }^{61}$. En España, los decretos de declaración y prórroga del estado de alarma limitaron la libertad de circulación y la libertad de empresa, y, colateralmente, los derechos de reunión y manifestación, pero ni técnica ni materialmente los suspendieron, porque las garantías normativas y procesales de dichos derechos se mantuvieron intactas y el artículo 7 del Decreto 463/2020, de 14 de marzo, previó numerosas excepciones a la prohibición general de circular por vías públicas, tales como las salidas para la adquisición de alimentos, productos farmacéuticos y de primera necesidad; asistencia a centros y establecimientos sanitarios; desplazamiento al lugar de trabajo; retorno al lugar de residencia habitual; asistencia y cuidado a mayores, menores, dependientes, personas con discapacidad o personas vulnerables; desplazamiento a entidades financieras y de seguros; por causa de fuerza mayor o situación de necesidad; y cualquier otra actividad de naturaleza análoga, permitiendo, igualmente, la circulación de vehículos particulares por las vías de uso público para la realización de dichas actividades.

60 Tras denunciar que la afección de los citados derechos es inconstitucional y sólo podía superarse ese vicio mediante la declaración de un estado de excepción, Vox pasó a sostener que las medidas necesarias para evitar la propagación del virus podían adoptarse al amparo de la legislación sanitaria vigente, sin necesidad de estado excepcional alguno. Y la tesis fue asumida a primeros de mayo por el PP, principal partido de la oposición, lo que convirtió las votaciones parlamentarias de las últimas autorizaciones de prórroga del estado de alarma en un tormento oriental para el Gobierno. Sobre los límites de esta legislación ordinaria, L. CoTINO Hueso, «Los derechos fundamentales en tiempos de coronavirus. Régimen general y garantías y especial atención a las restricciones de excepcionalidad ordinaria», El Cronista del Estado Social y Democrático de Derecho, n. ${ }^{\circ} 86-87,2020$, pp. 98-100.

61 En Italia, el Consejo de Ministros declaró el stato di emergenza di rilievo nazionale el 31 de enero de 2020 por una duración de seis meses y la expansión de la enfermedad obligó a aprobar el decreto-legge n. ${ }^{\circ} 6$ de 23 de febrero de 2020, de «Misure urgenti in materia di contenimento e gestione dell'emergenza epidemiologica da COVID-19», que previó la suspensión del derecho de libre circulación, el confinamiento de personas, el cierre de empresas y actividades comerciales y la paralización de los medios de transporte, y el decreto-legge n. ${ }^{\circ} 11$ de 8 de marzo de 2020 de "Misure straordinarie ed urgente per contrastare l'emergenza epidemiológica», que suspendió el derecho de reunión. En Portugal, el presidente de la República declaró el estado de emergencia «com fundamento na verificação de uma situação de calamidade pública» (Decreto n. 14-A/2020, de 18 de marzo), que fue prorrogado hasta el 2 de mayo de 2020, fecha a partir de la cual el Gobierno declaró la situación de calamidad prevista en la Ley n. ${ }^{\circ}$ 27/2006, de 3 de junio, de Bases de Protección Civil, bajo la que se pueden mantener «limites ou condicionamentos à circulação ou permanência de pessoas ou veículos, cercas sanitárias e de segurança». Francia, por su parte, declaró el état d'urgence sanitaire, creado mediante Loi n. ${ }^{\circ}$ 2020-290, du 23 mars 2020, d'urgence pour faire face à l'épidémie de COVID-19, a fin de restringir la libertad de circulación, el derecho de reunión y la libertad de empresa, imponer confinamientos y autorizar requisas de bienes y servicios. La Loi n. ${ }^{\circ}$ 2020-546, de 11 de mayo de 2020, prorrogó el estado hasta el 10 de julio de 2020 . 
«El régimen de alarma — subrayó Cotino Hueso— permite severas restricciones de la libertad de circulación que no tienen ni que seguir la regulación orgánica $\mathrm{u}$ ordinaria. [...] Materialmente es difícil no considerar justificada e idónea la medida. Y pese a que pueden incidir sobre el contenido esencial, estas graves restricciones de la circulación aún siguen posibilitando niveles importantes de movilidad y circulación ${ }^{62}$. La afección de su contenido esencial no supone, sin embargo, que la libertad de circulación y otros derechos conexos hayan quedado suspendidos. El artículo 7 del Decreto 463/2020 no contiene propiamente prohibiciones, sino, como apuntó Leiva Escudero, un condicionamiento general de la circulación a que exista una causa esencial o justificada, con una cláusula abierta que contempla expresamente la «situación de necesidad»y «cualquier otra actividad de análoga naturaleza» ${ }^{63}$. Ello encaja con la posibilidad de condicionar la circulación al cumplimiento de determinados requisitos prevista en el artículo 11.a) LOAES y con el criterio de resolución de los conflictos de colisión de derechos fundamentales y valores constitucionales establecido en la STC 154/2002, según la cual «cuando se trata del conflicto entre derechos fundamentales, el principio de concordancia práctica exige que el sacrificio del derecho llamado a ceder no vaya más allá de las necesidades de realización del derecho preponderante» (FJ 12). La restricción de libertad de circulación y el confinamiento impuesto «constatan un hecho - la universal capacidad de propagar la enfermedad, imposible de individualizar- que delimita automáticamente la frontera de nuestros derechos con nuestra obligación de no hacer daño a los demás» ${ }^{64}$. La limitación de la libertad de circulación y la reclusión domiciliaria, ha abundado en este sentido Arroyo Gil, persiguen salvaguardar «otros derechos fundamentales (en primer lugar, el derecho a la vida del art. 15 CE) $\mathrm{u}$ otros derechos o bienes constitucionales (destacadamente, el derecho a la protección de la salud del art. 43.1 CE, y la tutela de la salud pública del art. 43. 2 CE), igualmente merecedores de protección. El matiz no es menor. [...] y más allá de las serias restricciones — que, no lo olvidemos, admiten excepciones- los derechos referidos no quedan en suspenso» ${ }^{65}$; tan sólo han sido limitados para conseguir un fin constitucionalmente legítimo. Y esas restricciones pueden considerarse idóneas, necesarias y proporcionadas en sentido estricto al superar los beneficios reportados a los perjuicios inferidos a la libertad de circulación.

Tampoco fueron suspendidos, y ni siquiera limitados, por la declaración del estado de alarma los derechos de reunión y manifestación, como la admisión de varios recursos contencioso-administrativos interpuestos contra las prohibiciones de las autoridades gubernativas de manifestarse evidenciaron y como el ATC 40/2020, de 30 de abril, que rechazó un recurso de amparo interpuesto contra una

62 L. Cotino Hueso, «Confinamientos, libertad de circulación y personal...», cit., p. 8.

63 G. LeIva Escudero, «Constitucionalidad de las restricciones a la libertad de circulación en el estado de alarma por el coronavirus Covid-19», Diario La Ley, n. ${ }^{\circ}$ 9636, 20.05.2020, p. 20.

64 T. De La Quadra-Salcedo, «Límite y restricción, no suspensión», El País, 8.04.2020.

65 A. Arroyo Gil, «¿Estado de alarma o estado de excepción?», Agenda Pública, 12 de abril de 2020. 
de ellas, subrayó, al considerar que dichos derechos seguían bajo su régimen ordinario, lo que no impidió al TC reconocer que ambos derechos, pese a no estar suspendidos, no son ni absolutos ni ilimitados y que la prohibición de ejercerlos el 1 de mayo dictada por la Subdelegación del Gobierno de Pontevedra había sido, al ponderar otros derechos y bienes constitucionales, como el derecho a la vida, la integridad física, la salud y la defensa del sistema de asistencia sanitaria, una limitación de su ejercicio absolutamente idónea, necesaria y proporcionada ante el grave riesgo de contagio existente y la magnitud de la pandemia ${ }^{66}$. «[... la limitación del ejercicio del derecho — subrayó la Sala Primera del TC en una suerte de aviso a navegantes - tiene una finalidad que no solo ha de reputarse como legítima, sino que además tiene cobertura constitucional bastante en los artículos 15 CE (garantía de la integridad física de las personas) y $43 \mathrm{CE}$ (protección de la salud), ambos tan intensamente conectados que es difícil imaginarlos por separado, máxime en las actuales circunstancias. Es aquí donde la finalidad de la medida restrictiva del ejercicio del derecho confluye con la justificación de la

66 Las salas de lo contencioso-administrativo de los tribunales superiores de Justicia de Navarra y Aragón admitieron sendos recursos preferentes y sumarios contra las decisiones de prohibición de los respectivos delegados del Gobierno y permitieron la celebración de ambas reuniones bajo ciertas condiciones: en Navarra, sólo participarían seis personas con suficiente separación entre ellas; en Aragón, la participación se limitó a sesenta ciudadanos en vehículos particulares con un único ocupante (STSJ NA 84/2020 y STSJ AR 224/2020).

Las salas de lo contencioso-administrativo de los tribunales superiores de Andalucía, Cataluña, Galicia, Madrid, Navarra y Extremadura, por el contrario, rechazaron los recursos presentados contra decisiones similares de la autoridad gubernativa tras considerar que, dada la gravedad de la crisis sanitaria a finales de abril, el ejercicio de los derechos de reunión y manifestación ponía en riesgo otros derechos y bienes constitucionales como la salud pública, la integridad física y la vida de las personas. En Andalucía, el TSJ con sede en Sevilla, prohibió las concentraciones convocadas por el Sindicato Andaluz de Trabajadores en Cádiz, Sevilla y Sanlúcar de Barrameda (STSJ AN /2020); en Cataluña, el conflicto traía causa de la concentración de protesta convocada por la CUP ante el Parlament el 25 de abril, que fue comunicada a una autoridad gubernativa manifiestamente incompetente (STSJ CAT 1223/2020); en Galicia, se refería a la prohibición de manifestación convocada el 1 de mayo por la Central Unitaria de Traballadores/as (STSJ GAL 914/2020); en Madrid, a la prohibición de la marcha convocada por La Falange para protestar contra la gestión de la crisis sanitaria llevada a cabo por el Gobierno de la Nación (STSJ M 1546/2020); en Navarra, a la prohibición de las caravanas de coches convocadas por el sindicato LAB en varias localidades (STSJ NA 83/2020), y en Extremadura, a la prohibición para realizar una concentración ante la sede de la Presidencia de la Junta de Extremadura sita en Mérida (STSJ EXT 312/2020). Frente a la resolución del Tribunal Superior de Justicia de Galicia, la Central Unitaria de Traballadores/as presentó un recurso de amparo del que trae causa el citado ATC de 30 de abril de 2020.

Tres semanas después, bajo la vigencia de la cuarta prórroga del estado de alarma en la que la mayoría del territorio nacional había pasado a la segunda fase de la llamada «desescalada» o retorno a la «nueva normalidad», las autoridades gubernativas permitieron las manifestaciones de protesta en vehículo privado convocadas por el partido político Vox. En algunos de los territorios que permanecían en fase cero, las manifestaciones sí fueron prohibidas, pero las SSTSJ 1096/2020 de Castilla y León y 1955/2020 de Madrid, y las SSTSJ 2047/2020, 2302/2020, 2319/2020 y 2323/2020 de Cataluña anularon dichas decisiones tras constatar que la pandemia había remitido y la situación sanitaria era sensiblemente mejor a la analizada por el TC a finales de abril. Un análisis doctrinal en L. Cotino HuEso, «La posible constitucionalidad de las manifestaciones bajo la COVID-19 y del decreto de alarma para el Tribunal Constitucional», 1 de mayo de 2020, en www.derechoscovid.com, y E. ArNaldo AlCubilla, «Salux populi est lex, sed lex superior est constitutio. El ejercicio del derecho de manifestación en el estado de alarma», Diario La Ley, n. ${ }^{\circ}$ 9637, 21.05.2020, quien, muy crítico con el ATC de 30 de abril, atribuye el fallo a criterios de oportunidad o de coyuntura que desdibujan el contenido esencial del derecho hasta hacerlo irreconocible. 
declaración del estado de alarma. Las razones que sustentan ambas son idénticas y buscan limitar el impacto que en la salud de los seres humanos, en su integridad física y en su derecho a la vida pueda tener la propagación del COVID-19» (FJ 4).

Y tampoco cabía suspender ni limitar, ni la declaración del estado de alarma lo hizo, el derecho de participación política, no obstante lo cual las elecciones autonómicas vascas y gallegas convocadas para el 5 de abril fueron dejadas sin efecto por decreto de los presidentes autonómicos respectivos debido a la imposibilidad material de celebrar los procesos electorales en plena crisis sanitaria ${ }^{67}$. Ambas decisiones, justificadas en el principio de necesidad y adoptadas sin otro apoyo que el principio de contrarius actus, fueron insólitas y demoraron el ejercicio del derecho de sufragio de millones de ciudadanos, pero no cabía otra opción: la continuación de los procesos era inconciliable con las medidas de confinamiento y distanciamiento social y la votación popular habría devenido impracticable.

Pese a su intensidad, en suma, ninguna de las citadas restricciones de derechos implicaron su suspensión: ni las previstas expresamente en el Decreto 463/2020 ni las derivadas materialmente de aquellas. La suspensión implica que la norma que reconoce el derecho ha perdido temporalmente su vigencia por mor de la declaración y, con ello, el derecho ha dejado de existir bajo su régimen jurídico ordinario. Pero si, como ocurrió bajo este estado de alarma, la norma que rige el derecho y sus garantías permanecen intactas, el derecho sigue existiendo, pese a hallarse afectado su contenido esencial. Y la legitimidad de sus restricciones sigue condicionada a la concurrencia del principio de proporcionalidad y a la existencia o no de derechos y bienes preponderantes ${ }^{68}$.

\section{CONSIDERACIONES FINALES}

Tras aprobarse la LOAES, la doctrina vaticinó al estado de alarma una escasa funcionalidad, por considerarlo inadecuado para enfrentar tanto catástrofes naturales,

67 Véanse, respectivamente, el Decreto 7/2020, del Lehendakari, por el que deja sin efecto la celebración de las elecciones al Parlamento Vasco del 5 de abril de 2020 debido a la crisis sanitaria derivada del Covid-19, y se determina la expedición de la nueva convocatoria (BOPV, n. $\left.{ }^{\circ} 55\right)$ y el Decreto 45/2020, por el que se deja sin efecto la celebración de las elecciones al Parlamento de Galicia de 5 de abril de 2020 como consecuencia de la crisis sanitaria de la COVID-19 (Diario Oficial de Galicia, n. ${ }^{\circ}$ 54). Un análisis doctrinal en E. Arnaldo Alcubilla, «La suspensión de la celebración de las elecciones comporta una nueva convocatoria integra», Diario La Ley, n. ${ }^{\circ}$ 9608, 6.04.2020. Ambas elecciones autonómicas fueron convocadas de nuevo el lunes 18 de mayo y se celebraron finalmente el 12 de julio de 2020.

68 «Si estuviera suspendida nuestra libertad de circulación — ha subrayado I. VILLAVERDE MENÉNDEZ-, el Estado podría impedir a su antojo cualquier desplazamiento, incluso los justificados, y sancionarnos y obligarnos a permanecer en nuestros domicilios sin que podamos esgrimir ante los tribunales nuestra libertad deambulatoria, porque ya no existe a estos efectos. Pero en la situación actual esto no es así. El Estado sólo puede sancionarnos si acredita que hemos incumplido las reglas del confinamiento, $[\ldots]$ y además todas sus acciones pueden ser judicialmente controladas para comprobar su proporcionalidad». Cfr. «COVID-19: la gran prueba de estrés para los sistemas constitucionales», The conversation, 14 de mayo de 2020. En el mismo sentido, J. URías MarTínez, «Estado de alarma y limitación de derechos: ni excepción, ni suspensión», AlRevesyalDerecho, 9.04.2020. 
tecnológicas o sanitarias, como situaciones de conflictividad social. Frente a las primeras, la legislación sectorial ordinaria preveía medidas suficientes cuya adopción revestía menores formalidades; frente a las segundas, la redacción del artículo 4.c) de la LOAES reducía considerablemente las posibilidades de su declaración y la imposibilidad de suspensión de derechos abocaba dicho estado a la inoperancia ${ }^{69}$. En los últimos diez años, sin embargo, el estado de alarma se ha declarado para enfrentar ambos tipos de emergencias. Y su activación ha resultado extraordinariamente eficaz. Lo fue, en diciembre de 2010, ante la paralización del servicio esencial del transporte aéreo desencadenada por el boicot laboral de los controladores al servicio de AENA. Y lo ha sido, en la primavera de 2020, frente a los efectos y altos niveles de contagio de una pandemia ante la que las medidas contenidas en la legislación sanitaria ordinaria, como la Ley Orgánica de Medidas Especiales en Materia de Salud pública y la Ley General de Salud Pública, resultaban absolutamente insuficientes. Pero la declaración de dichos estados de alarma, además de evidenciar la versatilidad de la institución y la funcionalidad que antes se le negaba, ha puesto de manifiesto las limitaciones e insuficiencias de su regulación legal, tanto por lo que respecta a las emergencias que permiten declararlo cuanto a las medidas susceptibles de adoptar.

El legislador de la LOAES eliminó la cláusula abierta que encabezaba las circunstancias habilitantes del proyecto originario, mudó la relación enunciativa de emergencias en una pretendidamente taxativa y anuló como supuesto autónomo la paralización de los servicios públicos esenciales para la comunidad si no concurría al tiempo otra de las circunstancias contenidas en el artículo 4. Con ello, se pretendía limitar el estado de alarma a las emergencias de origen natural y evitar su utilización ante conflictos sociales que, provocados por el abuso de derechos o el incumplimiento de deberes, podían paralizar servicios esenciales. La realidad, sin embargo, se ha encargado de evidenciar lo vano de este intento, así como el error de pretender una tipificación taxativa de las situaciones excepcionales, sobre el que advirtió Porres Azcona ${ }^{70}$. Conforme a la absurda literalidad del artículo 4.c) de la LOAES, la declaración del estado de alarma en diciembre de 2010 no precedía, pero la misma doctrina que subrayó su improcedencia ha reconocido, al amparo de los principios de urgencia, necesidad y proporcionalidad, que el estado de excepción habría llegado tarde y habría resultado igualmente inadecuado ${ }^{71}$.

69 P. Cruz Villalón, Estados excepcionales y suspensión de garantías, cit., p. 70.

70 Debido a la dificultad para prever todos los supuestos bajo los que la excepción puede presentarse, su descripción debía tener «más el carácter de apertura de un procedimiento especial de manifestación de la voluntad del Estado, a partir de la interpretación que realiza el titular de los poderes extraordinarios sobre su propia competencia, que el de la descripción jurídica de una situación incontrovertible». J. Porres AzKONA, «La decisión sobre poderes excepcionales», RVAP, n. ${ }^{\circ}$ 6, 1983, pp. 46-47.

71 C. Vidal Prado y D. Delgado Ramos, «Algunas consideraciones sobre la declaración del estado de alarma...», cit., p. 255 y S. Siera Mucientes, «Los estados excepcionales», cit., pp. 378 y 390. 
El legislador de la LOAES también enumeró taxativamente las medidas aplicables bajo cada estado, pero, dado el carácter imprevisible de las situaciones de emergencia, su capacidad para regular apriorísticamente las respuestas adecuadas a las circunstancias fue muy limitada, como de nuevo la realidad excepcional ha revelado. En ambos estados de alarma, las restricciones han ido más allá de las previstas expresamente y han evidenciado la tenue línea existente entre la limitación y la suspensión de derechos. En 2010, se consideraron excesivas la militarización de los controladores aéreos y su sumisión a las leyes militares, aunque, sin dicha militarización, las órdenes del jefe del Estado Mayor del Ejército del Aire no habrían surtido efecto alguno. En 2020, se ha criticado la intensidad de las restricciones de la libertad circulatoria, el confinamiento domiciliario y la extrema limitación de las relaciones grupales, que produjeron la afectación en cadena de otros derechos. En nuestra opinión, ninguna de estas medidas supuso una suspensión de derechos, pero lo cierto es que resultaron tan duras que, como subrayó Cruz Villalón, difícilmente cabía encontrarlas acabadamente reflejadas en ninguno de los estados de emergencia previstos, ni describirlas «con arreglo a las categorías constitucionales disponibles» ${ }^{72}$. La pandemia, reconoció el ATC $40 / 2020$, de 30 de abril, revistió por sus efectos «dimensiones desconocidas hasta la fecha. Desconocidas y, desde luego, imprevisibles cuando el legislador articuló la declaración de los estados excepcionales en el año 1981» (FJ 4).

En este trabajo hemos sostenido que las insuficiencias de la LOAES en punto a la regulación de los supuestos habilitantes de la declaración podían ser superadas mediante una interpretación constitucionalmente conforme con la irreductible naturaleza bifronte del estado de alarma, instrumento útil a un tiempo ante catástrofes y crisis sanitarias y frente a ciertos conflictos sociales que, al no alterar significativamente el orden público, no requieren la suspensión generalizada de derechos. Y también hemos defendido que la rigidez e insuficiencia de las medidas standard contenidas en la LOAES no impiden la adopción de otras medidas excepcionales requeridas por las circunstancias, si resultan constitucionalmente legítimas al amparo de los principios de urgencia, necesidad y proporcionalidad asumidos por la LOAES y consustanciales al derecho de excepción. Pero debemos ser conscientes, con todo, de que la interpretación y la ponderación para salvar las carencias de la LOAES tienen su límite. Y que este límite podría traspasarse en la próxima emergencia.

Con la regulación actual del estado de alarma corremos el riesgo de incurrir en situaciones extrajurídicas para las que no exista otra disculpa que la razón de

72 P. Cruz Villalón, «La Constitución ante el estado de alarma», cit. «Nuestro ordenamiento jurídico — afirmó en el mismo sentido J. BARNES — , como el de tantos otros países, no estaba preparado para hacer frente a esta pandemia. El estado de alarma se quedaba corto; el de excepción, largo. Las leyes sanitarias estaban diseñadas para actuaciones localizadas y de respuesta rápida, pero no para un confinamiento generalizado de la población. Las medidas que ofrece nuestro Derecho son, en cierto modo, insuficientes e imperfectas. Y, sin embargo, "con estos bueyes hay que arar"». Cfr. «Un falso dilema», El País, 14.08.2020. 
Estado. No debemos llegar a eso. Pese a sus singularidades, el derecho de excepción es también derecho y su proyecto normativo no puede disolverse en la facticidad, por excepcional que esta resulte. Urge, por tanto, la reforma de la LOAES; una reforma en la que el legislador debería recuperar la relación meramente enunciativa de los supuestos habilitantes del estado de alarma, asumir su naturaleza bifronte y clarificar su operatividad en situaciones de conflictividad social. Y en la que, por lo que respecta a sus efectos, debería asimismo regular un nuevo elenco de medidas modulable en función de la gravedad de la emergencia, potenciar el papel de las CC.AA. en su aplicación, determinar el significado de la medida de movilización colmando el vacío existente e incluir una cláusula abierta que permita adoptar otras medidas de similar naturaleza a las previstas, pero que puedan requerir las circunstancias, con el único límite de la suspensión de derechos constitucionalmente reservada para los estados de excepción y de sitio. Es el momento idóneo para estudiar y acometer esta reforma ${ }^{73}$. El estado de alarma no es una amenaza, sino una garantía extraordinaria que, en circunstancias críticas, evita la improvisación y la inseguridad jurídica. Desterremos la demonización que este instrumento padece por motivos exclusivamente políticos, reconozcamos su utilidad y aprovechemos las lecciones que la crisis de la COVID-19 proporciona para mejorarlo.

TitLE: The Two-faced Nature of the State of Alert and the Dilemma of Rights Limiting-Suspension

AвSTRACT: The state of alert was considered an instrument of dubious utility. To fight natural, health or technological crises, the sector-specific legislation provided for several extraordinary measures that, according to the doctrine, made it unnecessary to resort to this regime. The preventions set out in its legal

73 Lamentablemente, no parece ser esta la prioridad del legislador. En el trascurso de las negociaciones del Gobierno con ERC y Ciudadanos con ocasión de la sexta prórroga del estado de alarma declarado por la COVID-19, se alcanzó el compromiso de «reformar la legislación sanitaria para hacer frente a futuras emergencias sin necesidad de recurrir al estado de alarma», lo que, de materializarse, normalizaría la adopción de medidas excepcionales generalizadas limitativas de derechos fundamentales sin las garantías jurídicas de dicho estado. Y sólo por eludir el impacto político de su declaración y las formalidades de su prórroga y por evitar las críticas que, vertidas por motivos fundamentalmente políticos, han pretendido demonizar el uso de este estado. El resultado no podría ser más paradójico. Debido a ello y a las dudas de constitucionalidad que suscita, el Gobierno ha renunciado por el momento a impulsar dicha reforma de las leyes sanitarias, se ha limitado a reformar la LJCA para atribuir el control de las medidas sanitarias de las CCAA a sus Tribunales Superiores de Justicia y ha invitado a las CCAA que lo precisen a solicitar la declaración de estados de alarma territorialmente delimitados, en los que los presidentes autonómicos serían la autoridad delegada. La invitación no ha sido aceptada, porque las autoridades autonómicas han considerado la solicitud de declaración de un estado de alarma limitado a su territorio un estigma político y han preferido, como la presidenta de la Comunidad de Madrid en octubre de 2020, que sea el Gobierno quien se vea forzado a declararlo, endosándole así la responsabilidad política y los costes de la decisión, adoptada mediante el RD 900/2020, de 9 de octubre. Dos semanas después, ante el aumento generalizado de los contagios, diez CCAA y la ciudad autónoma de Melilla han solicitado la declaración del estado de alarma en todo el territorio nacional, lo que el Gobierno ha materializado mediante el RD 926/2020, de 25 de octubre (BOE, n. ${ }^{\circ} 282$, de 25 de octubre). 
regulation hindered its use in situations of social conflict. The state of alert, however, was declared in December 2010, to reestablish the essential public service of air transportation — which had been cut by the strike of the air traffic controllers working for AENA - and in March and October 2020, to control the health crisis caused by the COVID-19 pandemic. Both situations have evinced the limitations and inadequacies of the legal regulation of this regime, both regarding the critical situations that allow to declare it and the measures that can be adopted. This work delves into the two-faced nature of the state of alert and the interpretation difficulties arising from its activation to tackle social conflicts and other emergencies that go beyond its legal framework. There is also an analysis of the problem of differentiating between limiting and suspending rights that lies behind the catalog of measures of this regime, the criticisms to its declaration in 2010 and the intense doctrinal debate resulting from the restrictions to the freedom of movement, the lockdown and the violation of other connected rights such as the right to reunion, to protest and to vote during the critical COVID-19 crisis.

Resumen: El estado de alarma fue considerado un instrumento de dudosa utilidad. Frente a las crisis naturales, sanitarias o tecnológicas, la legislación sectorial ordinaria preveía diversas medidas extraordinarias que, a juicio de la doctrina, hacían innecesario recurrir a dicho estado. Y las prevenciones introducidas en su regulación legal, dificultaban su uso ante situaciones de conflictividad social. El estado de alarma se declaró, sin embargo, en diciembre de 2010, para restablecer el servicio público esencial del trasporte aéreo paralizado por los controladores al servicio de AENA, y en marzo y octubre de 2020, para superar la crisis sanitaria ocasionada por la pandemia de la COVID-19. Ello ba evidenciado la versatilidad de la institución y la funcionalidad que antes se le negaba, pero también han puesto de manifiesto las limitaciones e insuficiencias de su regulación legal, tanto por lo que respecta a las situaciones críticas que permiten declararlo cuanto a las medidas susceptibles de adoptar. En este trabajo se analiza la naturaleza bifronte del estado de alarma, junto a las dificultades interpretativas que suscita su activación frente a conflictos sociales y otras emergencias que desbordan su marco jurídico. Asimismo, se abordan el problema de la distinción entre limitación y suspensión de derechos que subyace bajo el elenco de medidas de este estado, las críticas que desencadenó su declaración en 2010 y el intenso debate doctrinal que han generado las restricciones a la libertad de circulación, la reclusión domiciliaria y la afección de otros derechos conexos, como los de reunión, manifestación y sufragio, durante la gravísima crisis de la COVID-19.

KEY WORDS: state of alert, law of exception, rights limiting, Covid-19 crisis.

Palabras clave: estado de alarma, derecho de excepción, limitación de derechos, crisis Covid-19.

FECHA DE RECEPCIÓN: 09.05.2020

FECHA DE ACEPTACIÓN: 09.09.2020 